\title{
The contributions of the European Medicines Agency and its pediatric committee to the fight against childhood leukemia
}

This article was published in the following Dove Press journal:

Risk Management and Healthcare Policy

5 November 2015

Number of times this article has been viewed

\author{
Klaus Rose ${ }^{1, *}$ \\ Philip D Walson ${ }^{2, *}$ \\ 'klausrose Consulting, Pediatric Drug \\ Development and More, Riehen, \\ Switzerland; ${ }^{2}$ Department of Clinical \\ Pharmacology, University Medical \\ School, Goettingen, Germany
}

*These authors contributed equally to this work
Correspondence: Klaus Rose klausrose Consulting, Pediatric Drug Development and More, Aeussere Baselstrasse 308, 4I 25 Riehen, Switzerland

Tel +4I 6I 31205I0

Email klaus.rose@klausrose.net
Background: Although the diagnosis of childhood leukemia is no longer a death sentence, too many patients still die, more with acute myeloid leukemia than with acute lymphoblastic leukemia. The European Union pediatric legislation was introduced to improve pharmaceutical treatment of children, but some question whether the European Medicines Agency (EMA) approach is helping children with leukemia. Some have even suggested that the decisions of EMA pediatric committee (PDCO) are counterproductive. This study was designed to investigate the impact of PDCO-issued pediatric investigation plans (PIPs) for leukemia drugs.

Methods: All PIPs listed under "oncology" were downloaded from the EMA website. Nonleukemia decisions including misclassifications, waivers (no PIP), and solid tumors were discarded. The leukemia decisions were analyzed, compared to pediatric leukemia trials in the database http://www.clinicaltrials.gov, and discussed in the light of current literature.

Results: The PDCO leukemia decisions demand clinical trials in pediatric leukemia for all new adult drugs without prioritization. However, because leukemia in children is different and much rarer than in adults, these decisions have resulted in proposed studies that are scientifically and ethically questionable. They are also unnecessary, since once promising new compounds are approved for adults, more appropriate, prioritized pediatric leukemia trials are initiated worldwide without PDCO involvement.

Conclusion: EMA/PDCO leukemia PIPs do little to advance the treatment of childhood leukemia. The unintended negative effects of the flawed EMA/PDCO's standardized requesting of non-prioritized testing of every new adult leukemia drug in children with relapsed or refractory disease expose these children to questionable trials, and could undermine public trust in pediatric clinical research. Institutions, investigators, and ethics committees/institutional review boards need to be skeptical of trials triggered by PDCO. New, better ways to facilitate drug development for pediatric leukemia are needed.

Keywords: childhood leukemia, better medicines for children, pediatric drug development, therapeutic orphans, therapeutic hostages, ghost studies, pediatric investigation plan

\section{Cancer and leukemia in children}

Childhood cancer has moved from just a footnote in pediatric textbooks to the major cause of death from disease in the children of developed countries. ${ }^{1}$ Diseases that in the past caused horrendous death rates in children can today either be prevented by vaccination, better nourishment, housing, hygiene, and more - or be treated by antibiotics, antivirals, and other medications. The increasing capacity to overcome these child killers of the past has given child cancer a sad prominent position. Together, acute lymphoblastic leukemia (ALL) and acute myeloid leukemia (AML) make up approximately one-third of all pediatric cancer diagnoses. ${ }^{2}$ The diagnosis of leukemia is 
no longer an automatic death sentence, as it was a century ago. But survival of child cancer is not like overcoming a serious infection that a year later is just a bad remembrance. For both ALL and AML, treatment fundamentally is based on cytotoxic drugs that cause intracellular damage, resulting in the death of leukemia blasts., ${ }^{3,4}$ Despite remarkable improvement, the prognosis of certain high-risk groups of leukemia and of relapsed disease remains poor, more so in AML but also in a small percentage of children with ALL. ${ }^{5-7}$

Specialized centers differentiate patients at first diagnosis into subgroups. Patients are then treated in a risk-adapted fashion; that is, low-risk patients receive relatively moderate chemotherapy (CT), and high-risk patients receive rather toxic doses. ${ }^{6,7}$ Once treatment has started, the waiting and despair starts: Will remission be achieved? Will it hold? In patients with relapsed or refractory $(\mathrm{R} / \mathrm{R})$ leukemia, a second round of treatment starts, but the chances for a new remission are less good. Because high-risk patients are identified relatively soon, it is debatable whether they might be better served by enrollment into Phase II window studies, where early exposure to a novel drug might lead to improved efficacy compared to the conventional regimen or later exposure to the novel drug. ${ }^{5}$

In adult cancer, there is a competitive search for new ways to help. Only a part of this competition is guided by science. Patients in despair can also fall prey to quack healers and swindlers. Even within the science-driven approach(es), the competition is fierce. Academic researchers, big pharmaceutical companies, and small start-up companies compete. Companies either invest their own money or find money on the financial investment market or in the philanthropic world. The research and development machinery of the big pharmaceutical industry may be successful to some degree but has also become bureaucratic and inert. Increasingly, big companies let drug discovery be done by start-up companies. If a start-up company reaches certain milestones in development, it will be bought entirely, sell its compound, or codevelop it with a big company. The litmus test in drug development is success in real patients. The pivotal clinical trials aim at regulatory approval. To accept or reject approval is the key task for regulatory authorities.

As outlined by many authors, the pediatric cancer market is rather limited due to its rarity. ${ }^{1,3,8,9}$ There is also broad agreement within the pediatric oncology clinical community that major steps forward need to come out of biomedical research, involving our increasing understanding of the body on a cellular and subcellular level. ${ }^{1,3,9}$ Furthermore, in cancer and even in leukemias, the adult disease differs considerably from the childhood disease. There has been considerable progress toward targeted therapy in adult oncology, and there is broad agreement that comparable steps toward better treatment of childhood cancer would be desirable but difficult to achieve.

A complex, highly successful industry has evolved, and continues to evolve, that develops products (drugs, devices, and diagnostic products) that can prevent, cure/control, or diagnose human diseases. This industry is market-driven but is also influenced by numerous interactions with government, academia, and society. Governmental influence comes largely from regulatory bodies that approve products for marketing. Regulatory authority is based on legislation, much of which was developed to deal with patient harm caused by an unregulated pharmaceutical industry such as the use of ethylene glycol in sulfanilamide, ${ }^{10}$ and deformed newborns from thalidomide. ${ }^{11,12}$ Legislation enacted to prevent such public health disasters resulted in the current US Food and Drug Administration (FDA) ${ }^{12}$ and later its counterparts in other regions, in the European Union (EU) today the European Medicines Agency (EMA) ${ }^{13}$ that works as an umbrella with the EU national authorities.

This review focuses on the effects of the EU pediatric legislation ${ }^{14}$ designed to force the pharmaceutical industry to consider children in drug development, and takes pediatric leukemia as a paradigm. We start with a discussion of some important points that are frequently misperceived.

1. The US pediatric legislation was not designed to and does not facilitate the development of better medicines for children. Details of the US pediatric legislation have been described in detail elsewhere. ${ }^{3,15}$ In a nutshell, the original first law, Food and Drug Administration Modernization Act, offered a reward for additional pediatric data, mostly pharmacokinetics/pharmacodynamics, and sometimes additional efficacy data, for existing adult drugs. Its goal was to provide labeling on whether or how drugs developed for adults (and that still had patent protection) should be used in children. This very successful legislation was of great interest to the research-based pharmaceutical industry that had started to feel the threat of patent expiry of several top-selling products. A second legislation, Pediatric Research Equity Act, gave the FDA the authority to mandate clinical trials be done in children for new drugs where a relevant pediatric use could be expected because the same disease existed in both adults and children. Such additional information is precious, but its value needs to be differentiated for the different childhood age groups. Absorption, distribution, metabolism, and excretion of drugs are different between 
children and adults, but the clinical relevance of this is greater in infants and young children than in adolescents. The US pediatric legislation promoted the use of the development machinery of the pharmaceutical industry for the first time to do pediatric clinical trials, ${ }^{16}$ but it was never designed to develop new drugs specifically for children. In this sense, the term "pediatric drug development"17,18 is misleading, as so far, this term addresses more the inclusion and co-consideration of children into the drug development process for adult drugs.

2. When academics discuss the history of pediatric oncology drug development, they emphasize the key role of academic researchers.

The success reported by Farber et $\mathrm{al}^{19}$ in 1947 , on the efficacy of aminopterin, a folate antagonist and precursor to methotrexate, might well be heralded as the dawn of childhood cancer CT and, possibly, as the beginning of all new anticancer agent development. ${ }^{3}$

In the era after Farber,

[...] Frei et $\mathrm{al}^{20}$ achieved a complete remission rate of $59 \%$ using a combination of mercaptopurine and methotrexate. [...] Pinkel and colleagues ${ }^{21}$ [...] in 1962 initiated a novel curative approach ("total therapy") to ALL treatment $[\ldots] .^{22}$

The merits of Farber's, Frei's, and Pinkel's achievements are beyond question. But the descriptions above fall short of capturing how this newly evolving framework came about. How did Dr Farber have access to aminopterin? Where did the "several new antileukemia drugs"22 come from? They were "around" because they could be ordered or could be produced in a local laboratory - because the chemicals and laboratory equipment were "available". The history of pediatric oncology was the systematic study and use of drugs in children developed and brought to the market for adult patients by the - then - chemical industry. New anticancer drugs became broadly available because they were FDA-approved. Adamson describes how the 5-year survival for children with ALL improved from the 1970s through the 1990s and that in this period major new drug discoveries happened.

Quite remarkably, almost all of the drugs used in the treatment of childhood ALL that drove this improvement were primarily discovered and developed in the 1950s and 1960s. ${ }^{1}$

Where did they come from? They were not parachuted by god to the FDA for approval. They had to be developed, tested, and made available to gain approval by the FDA. This included transition from small batches to full-size industrial production. This required skills in addition to scientific curiosity and the zeal to make a clinical career. In other words, the emphasis on academic achievements ignores a critical part of this story that is relevant for any attempt to use the pharmaceutical industry's research, discovery, and development machinery with the aim of developing better drugs for children.

3. Regulatory authorities are crucial in keeping quack medicines and dangerous compounds from the market and (from the 1960s) in demanding proof of efficacy of new drugs before their market introduction, including anticancer drugs. Regulators made no specific contribution to pediatric oncology. All FDA-approved drugs, now "around", were used off-label, and many of them are still not FDA-approved for use in children. ${ }^{8,15,16}$

4. The pharmaceutical industry is not static. Companies compete, merge, go through acquisition, or go bankrupt. When the new era of targeted medicine started with the success of the first targeted medicines, the tyrosine kinase inhibitors (TKIs) in Philadelphia chromosome-positive $(\mathrm{Ph}+)$ leukemia, there were great expectations that personalized medicine would develop rapidly, but successes were slower and more limited than expected. Increasingly large pharmaceutical companies rely less on in-house research and development and more on licensing in new compounds that have been developed by smaller, more flexible start-up companies.

5. The EU pediatric legislation was a follow-up to the US legislation. Superficially, it might appear comparable, but there are considerable differences. The key difference is that the EU version makes pediatric development for each new adult drug mandatory, unless the adult disease does not exist in children, the drug is unsafe, or no additional therapeutic benefit can be expected in children. Discussion and decisions about what should be done in children must be performed long before proof of efficacy: at the end of Phase I. At this time point, the submission of a pediatric investigation plan (PIP) is expected. The process by which the PIP is then discussed with the EMA pediatric committee (PDCO) takes $\sim 1$ year. Without an accepted PIP, approval of the drug is blocked. Details

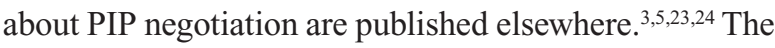
EU pediatric legislation is based on the assumptions that the key to better medicines for children lies in biomedical research, which to a large degree is run by the pharmaceutical industry, and that this industry needs guidance by the 
EMA, whether wanted or not, to test and label drugs for use in children because the off-label use of drugs can be unhelpful or even dangerous. While true for many drugs specifically in young children and infants, this is not true for pediatric oncology drugs.

6. The off-label use of oncology drugs is routine in pediatric oncology and in the hands of well-trained specialists. Such use has saved thousands of lives. Pediatric oncology is certainly not good justification for the introduction of the pediatric legislation. For decades, the childhood cancer cooperative groups have prioritized and systematically tested all promising drugs in children with cancer.

The basic question this paper asks is the following: Will the EMA/PDCO's decisions advance the treatment of childhood leukemia? To answer this question, all PDCO decisions related to childhood leukemia were therefore examined.

\section{The EMA AML standard PIP}

For AML, EMA and PDCO have developed a "standard PIP" to guide pharmaceutical companies that develop new drugs against adult AML. ${ }^{25}$ This document allows insight into PDCO's logic. It starts with the explanation that there are still unmet therapeutic needs in children with newly-diagnosed AML as well as in those with R/R AML and continues that all pediatric AML subsets,

[...] should be discussed in the PIP documentation and the PIP indication should target 2 or 3 of the following subsets, selected based on a scientific rationale for the medicine and with the objective to improve the overall outcome in AML.

Table 1 shows these subsets.

With the standard PIP's logic, companies must for each new anti-AML drug pick two to three AML subgroups and "propose" clinical trials and other measures (child-friendly formulations, preclinical toxicity studies, and more). If a company does not "propose" enough, the PIP will be refused, and the compound's approval is blocked, no matter how well it might work in adults. However, childhood leukemia is rare, and patients with $\mathrm{R} / \mathrm{R}$ AML or ALL are even rarer.

\section{EMA's PDCO cancer decisions}

The EMA website provides both a quick look at the current pipeline of industry's pediatric leukemia drugs and a listing of PDCO decisions concerning these drugs. A search was conducted at "Opinions and decisions on paediatric investigation plans" by "browsing from a to z", keywords, or therapeutic area. As of July 27, 2015, there were 122 PIP decisions identified under "oncology". ${ }^{26}$ Waivers (no pediatric development
Table I Subgroups in the EMA/PDCO AML standard PIP

- Patients with newly-diagnosed high-risk AML: need for a more efficacious treatment as part of a first-line induction regimen, in particular when there is a good rationale for use during first-line treatment, such as the individual disease biology (eg, FLT3 mutations with high allelic ratio etc) or the potential for reduction of toxicity.

- Patients with AML that is resistant to first or to second line induction. treatment: need for an efficacious treatment as part of a re-induction regimen.

- Patients at the time of diagnosis of relapse after HSCT/second or subsequent relapse: need for an efficacious treatment that is not overly toxic in this subset of patients who likely had high cumulative previous treatment exposure, likely including at least one prior transplant procedure.

- Patients with secondary AML: need for an efficacious treatment.

- Patients at the time of diagnosis of early first relapse: need for a more efficacious treatment as part of a treatment regimen.

- Patients at the time of diagnosis of first relapse (other than early): need for a more efficacious treatment as part of a treatment regimen.

- Patients with APL: need for safer treatment to be used during induction.

- Patients with AML in Down syndrome: Needs may exist, specifically for non-cytotoxic or "targeted" medicines to reduce treatment toxicity. Needs may be less in patients younger than I year of age and in those with $F A B M 6$ or M7, compared to other patients with $A M L$ in Down syndrome.

- Congenital AML, extramedullary AML.

Notes: The content of this table contains the wording of the AML pediatric subgroups from the AML standard PIP. Underlinings, explanations in brackets, and quotation marks are exact copies of the AML standard PIP.

Abbreviations: EMA, European Medicines Agency; PDCO, pediatric committee; AML, acute myeloid leukemia; PIP, pediatric investigation plan; $\mathrm{HSCT}$, hematopoietic stem cell transplantation; APL, acute promyelocytic leukemia; FAB, French-American-British.

required) and wrongly classified PIPs, etc were discarded. In one case, the EMA overview listed a PIP modification, but the document shows it is now a waiver. Two decisions were listed twice. For a colony-stimulating factor (CSF), there were two decisions: one to refuse a waiver (EMEA-001042-PIP01-10) and a later PIP decision (EMEA-001042-PIP02-11). Waiver requests are either accepted or rejected. If rejected, the applicant must start a new PIP procedure. The CSF manufacturer submitted a new PIP and got approval, so only the CSF PIP decision was counted.

Published PIP decisions have two parts. The first pages declare officially that the PDCO has given an opinion and has come to a decision. In the second part, under "Opinion of the Paediatric Committee", key information is listed: name of the drug, the disease in which it should be developed for children, its pharmaceutical form, etc. The key elements, that is, which clinical studies and other actions must be done (after the "applicant" has "proposed" them), are summarized in a table at the end of the PIP decision. Some of the "conditions" listed under the headline "Opinion of the Paediatric 
Committee" were not completely congruent with the clinical studies. Several drugs target both adult ALL and AML. First, all compounds from the original 122 PIP opinions that contained a type of leukemia under the headline "Opinion of the Paediatric Committee" were double-checked to see if the studies corresponded to these two conditions. For example, the rituximab PIP EMEA-000308-PIP01-08-M02 has as condition(s) "Treatment of diffuse large B-cell lymphoma" and "Treatment of autoimmune arthritis", but the key elements list a clinical study on "B-cell lymphoma (excluding primary mediastinal B-cell lymphoma), Burkitt and Burkitt-like lymphoma/leukaemia". Therefore, rituximab was included. Obinutuzumab has under the headline "Opinion of the Paediatric Committee" as condition(s) "Treatment of mature B-cell lymphoma" and "Treatment of acute lymphoblastic leukaemia", but the PIP study listed is only in children with mature B-cell lymphoma; hence, the obinutizumab PIP was not included into the leukemia PIP analysis.

The classification of all compounds and additional explanation is given in Supplementary materials (Table S1-S4), including detailed explanation of misclassifications and double listings (Table S2-S4). The algorithm to identify the leukemia PIPs is given in Figure 1. The 17 PIP decisions for AML and ALL are listed in Tables 2 and 3.

With the exception of mercaptopurine, all AML and ALL PIP decisions have an open-label dose-escalating trial plus, in most cases, additional studies of population pharmacokinetics/pharmacodynamics, safety, efficacy, feasibility, or activity. There is no prioritization of the compounds. As pointed out by others, this is a drug-centered and not a disease-centered approach. ${ }^{1,5}$ It requests the same studies for every drug being developed for adult leukemia, an approach that might make sense if leukemia were as common in children as it is in adults and if childhood leukemia were the same disease as adult leukemia. However, cancers in children, including AML and ALL, are different from cancers in adults, and are much rarer.

The EMA/PDCO's decisions appear to be based on the assumption that every new, but as yet unstudied, adult antileukemia compound has an equal chance of having a beneficial effect in children as well.

There are three problems with the EMA/PDCO's decisions. Firstly, they reflect an unprioritized, drug-centric approach. ${ }^{1,5}$ Secondly, the number and type of studies might be justified and possible if there were an unlimited number of pediatric patients, but there are not. Finally, the approach ignores the fact that these drugs will be and are being studied in other countries. All studies compete for both investigators and patients worldwide.

To analyze to what degree the PIPs translate into clinical trials that compete for patients, all drugs with a leukemia PIP decision were looked for in the database http://www. clinicaltrials.gov. This is the world's largest registry of clinical trials, run by the US National Library of Medicine. Currently, it includes registrations of $>190,000$ trials from $>170$ countries. In comparison, the EU clinical trials database http://www.clinicaltrialsregister.eu is less user friendly and minimally helpful for research like this. For example, the search terms "rituximab leukemia children" resulted in three hits, of which one was in adults only, and the search terms "decitabine children leukemia" resulted in two hits, of which one was a study in adults.

As shown in Table 4, once drugs are approved in adults, they can be used in multiple studies conducted worldwide to investigate their potential use in children. However, as illustrated by some drugs selected from Tables 2 and 3, there are major differences between the PDCO approach and the more selective approach taken outside EMA/PDCO (Table 4).

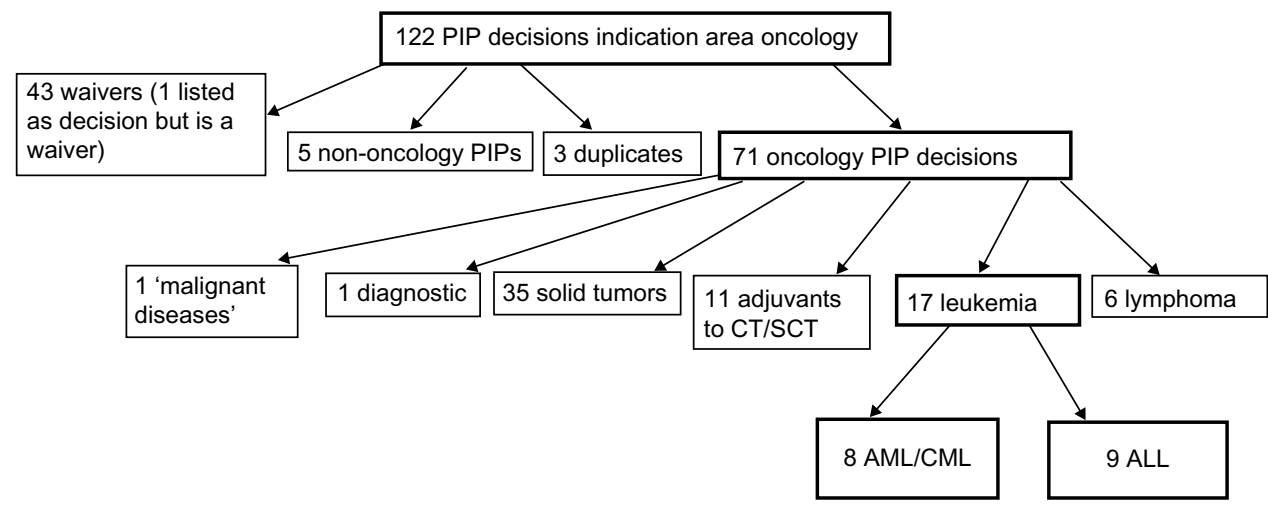

Figure I Classification of PIP decisions.

Abbreviations: PIP, pediatric investigation plan; SCT, stem cell transplantation; AML, acute myeloid leukemia; CML, chronic myeloid leukemia; ALL, acute lymphoblastic leukemia; CT, chemotherapy. 
Table 2 AML/ CML PIP Decisions

\begin{tabular}{ll}
\hline Drug, PIP \# & Clinical Studies \\
\hline Bosutinib & I. OL MC uncontrolled, DF study to evaluate PK, S and A of bosutinib in 10 to $<18$ years w/Ph+ CML in \\
EMEA-000727- & $\begin{array}{l}\text { chronic phase resistant/intolerant to prior TKI therapy } \\
\text { PIP0I-09 }\end{array}$
\end{tabular}

Decitabine EMEA-000555PIP0I-09-M04

Elacytarabine EMEA-00II2IPIPOI-IO

Midostaurin EMEA-000780PIPOI-09-M0I

Nilotinib EMEA-000290PIPOI-08-M03

\section{Ponatinib} EMEA-00I I86PIPOI-I I

Volasertib EMEA-000674PIP02-I I

Vosaroxin EMEA-00I450PIPOI-I3
I. OL MC multiple dose trial to evaluate PK, S and A of decitabine in sequential combination with cytarabine in children I month to $<18$ years with $A M L$

2. OL, MC, $R$ controlled trial to evaluate $S$ and $E$ of decitabine in sequential combination with cytarabine compared with standard of care induction therapy in children I month to <I8 years with AML

I. OL, uncontrolled, dose-escalating trial to evaluate $S$, tolerability and PK of elacytarabine in patients I month to $<18$ years $w / R / R$ acute leukaemia

2. OL externally controlled trial to evaluate $\mathrm{S}, \mathrm{A}$ and $\mathrm{E}$ of elacytarabine in combination with liposomal daunorubicin compared to fludarabine, cytarabine and daunorubicin in patients I month to $<\mid 8$ years $w /$ $\mathrm{R} / \mathrm{R}$ AML with an initial DE stage to $\mathrm{S}$ of elacytarabine in combination with liposomal daunorubicin

I. OL DE, single-agent, MC, age-stratified trial to evaluate toxicity, PK, PD, S and A of midostaurin in 3 months to $<18$ years w/ R/R ALL or AML

2. OL DE, randomized, active-controlled, age-stratified, $M C$ trial to evaluate toxicity, $P K, P D, S$ and $A$ in children 3 months to $<18$ years with newly-diagnosed AML with certain FLT3 TKD mutation burden

3. Pop PK/PD and outcome model to support extrapolation of $E$

I. Study to compare bioavailability of nilotinib when administered as intact capsule or the capsule content mixed with yogurt or apple sauce in adult volunteers

2. Multiple-dose OL single-agent, non-controlled trial to evaluate PK, PD, S and A in patients I to $<18$ years $\mathrm{w} / \mathrm{Ph}+\mathrm{CML}$ in chronic or accelerated phase intolerant or resistant to imatinib- and/or dasatinib, or with $\mathrm{R} / \mathrm{R} \mathrm{Ph}+\mathrm{ALL}$

3. Multiple-dose $\mathrm{OL}$ single-agent, non-controlled, $M C$ trial to evaluate $P K, S$ and $A$ in patients $I$ to $<18$ years $\mathrm{w} / \mathrm{Ph}+\mathrm{CML}$ in chronic or accelerated phase, intolerant or resistant to imatinib- or dasatinib or with newly diagnosed $\mathrm{Ph}+\mathrm{CML}$ in chronic phase

I. OL, single-agent, DE, MC trial to investigate tolerability, S and A of ponatinib in children I-I7 years with malignant disease for which no effective treatment is known, and with an expansion cohort of children with chronic phase CML

I. OL, non-controlled, DE trial to evaluate PK, PD, tolerability and toxicity of volasertib in patients 2 to $<18$ years $\mathrm{w} /$ acute leukaemia or advanced solid tumour, for whom no effective treatment is known

SEP 2019 OL, DE trial to evaluate PK, PD, tolerability, toxicity, $\mathrm{S}$ and $\mathrm{A}$ of volasertib added to intensive CT in children 3 months to $<18$ years with AML after failure of front-line intensive $C T$

3. $\mathrm{OL}, \mathrm{R}$, controlled trial to evaluate $\mathrm{S}$ and $\mathrm{E}$ of volasertib integrated with a standard intensive $\mathrm{CT}$ regimen in children 3 months to $<18$ years with AML after failure of the front-line intensive $C T$

I. OL, uncontrolled, MC, DE trial to evaluate tolerability, S, PK and A of vosaroxin in children with acute leukaemia I month to $<18$ years

2. OL, uncontrolled, $M C$ trial to evaluate $S$ and $A$ of vosaroxin in combination with FLAG (fludarabine, cytarabine, filgrastim) in children I month to $<18$ years with a first relapse of $A M L$

Abbreviations: OL, open label; PK, pharmacokinetics; PD, pharmacodynamics; DF, dose-finding; $D E$, dose escalating; w/, with; R/R, relapsed or refractory; $B E$, bioequivalence; Pop PK/PD, Population PK/PD; MC, multicenter; E, efficacy; S, safety; A, activity; R, randomized; AML, acute myeloid leukemia; ALL, acute lymphoblastic/lymphocytic/ lymphoid leukemia; Ph+, Philadelphia positive; CT, chemotherapy; CML, chronic myeloid leukemia; PIP, pediatric investigation plan.

Decitabine, for example, is a DNA-hypomethylating agent that induces differentiation and apoptosis of leukemic cells, and is a well-tolerated alternative to aggressive CT. It is FDA-approved for myelodysplastic syndrome but is not approved for AML. ${ }^{27}$ There are currently 198 clinical studies with decitabine listed in clinicaltrials.gov, and 29 with the search terms "decitabine leukemia children". Out of these 29, 16 are listed as already being completed (Table 5).

There are also 66 trials listed for imatinib, 40 of which are listed as already completed. In contrast, bosutinib, the fourth
TKI developed after imatinib, was FDA-approved in 2012 (for adults with chronic, accelerated, or blast-phase $\mathrm{Ph}+$ chronic myeloid leukemia [CML] with resistance or intolerance to prior therapy) and has had conditional EMA approval in adults since 2013. The 2010 PIP decision on bosutinib lists a number of studies that are scheduled to be completed by December 2016. However, there is not a single pediatric leukemia study with bosutinib listed in http://www.clinicaltrials.gov.

As these examples illustrate, where clinicians (and parents) have hope, a number of adult and pediatric studies are opened 
Table 3 ALL PIP decisions: clinical studies

Autologous T-cells transduced

with lentiviral vector containing

a chimeric antigen receptor

directed against CDI9

(CTLOI9),

EMEA-00I654-PIPOI-I4

Navitoclax (ABT-263),

EMEA-000478-PIPOI-08-M0I

Blinatumomab,

EMEA-000574-PIP02-12

Dasatinib,

EMEA-000567-PIP0I-09-M04

Imatinib,

EMEA-000463-PIP0I-08-M03

L-Asparaginase encapsulated in erythrocytes,

EMEA-00034I-PIP02-09-M0 I

Mercaptopurine,

EMEA-000350-PIPOI-08

Recombinant L-asparaginase, EMEA-0000 I3-PIPO I-07-M03

Rituximab,

EMEA-000308-PIP0I-08-M02
I. OL SA posology-finding study to evaluate $S$ and $F$ of redirected autologous T-cells engineered to contain anti-CDI 9 attached to TCRzeta and 4-IBB signaling domains (CAR-19 cells) in patients I year to $<18$ years (and adults) with a CT-resistant or CT-refractory CDI9+ leukemia or lymphoma

2. OL SA, single-dose study to evaluate $S$ and $A$ of CTLOI 9 in 2 years to $<18$ years at the time of initial diagnosis (and adults) with CDI9+ B-cell acute LL/CDI9+ B-cell lymphoblastic lymphoma refractory to standard $\mathrm{CT}$, relapsed after SCT, or otherwise ineligible for allogeneic SCT

3. OL SA single-dose study to evaluate $S$ and $A$ of CTLOI 9 in 3 years to $<18$ years (and adults) with CDI9+ B-cell ALL refractory to standard CT, relapsed after SCT, or ineligible for allogeneic SCT

4. OL two-cohort study to evaluate manufacturing and $S$ of CTL019 in $<3$ years, weighing $\geq 6 \mathrm{~kg}$, with CDI9+ B-cell ALL/CDI9+ B-cell lymphoblastic lymphoma at high risk for relapse and at relapse or refractory stage

I. OL, S and PK study of ABT-263 single-agent and combination therapy in pediatric patients from 28 days to $<18$ years of age with relapsed or refractory lymphoblastic leukemia or lymphoblastic lymphoma

2. R, controlled, $S$ and $A$ study of ABT-263 in combination with a chemotherapeutic backbone in patients with relapsed or refractory lymphoblastic leukemia or lymphoblastic lymphoma

I. MC, OL, multiple-dose, dose-escalation trial to evaluate PK, PD, toxicity, $\mathrm{S}$, and antitumor activity of blinatumomab in children from birth to $<18$ years of age with a relapse of B-precursor ALL involving the bone marrow or a refractory ALL and for whom no effective treatment is known, with an extension phase R, controlled, adaptively designed, OL trial to evaluate the PK, S, and E of blinatumomab compared to multiagent consolidation CT in children from I month to $<18$ years of age with a first, high-risk relapse of B-precursor ALL PK-PD analysis to inform the dose for study 2

I. OL MC dose-escalation trial to evaluate PK and $\mathrm{S}$ of dasatinib in children from 2 years to $<18$ years (and in adults) with recurrent or refractory solid tumor or imatinib-resistant $\mathrm{Ph}+$ leukemia

2. OL MC dose-escalation trial to evaluate $P K$ and $S$ of dasatinib in children from I year to $<18$ years with $P h+C M L$ or acute leukemia

3. OL MC trial to evaluate PK, S, and E of dasatinib in children I year to $<18$ years with $\mathrm{Ph}+\mathrm{CML}$ of all phases (including treatmentnaïve patients in chronic phase) or relapsed or refractory $\mathrm{Ph}+\mathrm{ALL}$

I. OL MC non-R dose-escalation trial to evaluate $\mathrm{S}$ and $\mathrm{E}$ of $\mathrm{CT}$, hematopoietic SCT, and imatinib in children from I year to $<18$ years (and young adults) with ALL

2. OL MC R trial to evaluate $S, A$, and $E$ of imatinib on top of CT and in combination with hematopoietic SCT in children I year to $<18$ years with ALL

3. Development and validation of an integrated physiology-based PK and pop PK model

4. For the indications myelodysplastic/myeloproliferative diseases associated with platelet-derived growth factor receptor gene rearrangements, hypereosinophilic syndrome and/or chronic eosinophilic leukemia with FIPILIplatelet-derived growth factor receptor alpha gene rearrangement, kit (CD II7)-positive gastrointestinal stromal tumors, and dermatofibrosarcoma protuberans, the following studies are separately listed

- Study 3: same as for condition treatment of Philadelphia chromosome (BCR-ABL translocation)-positive ALL

- Study 4: measure to extrapolate efficacy to the pediatric population

I. Double-blind, dose-comparative, R, repeat-dose, MC, active-controlled trial to evaluate PK, PD, S, and immunogenicity of $L$-asparaginase encapsulated in erythrocytes in children from I year to $<18$ years (and in adults) with ALL

2. OL, R, single-dose, $M C$, active-controlled trial to evaluate $P K, S$, and PD activity of L-asparaginase encapsulated in erythrocytes in children from I year to $<18$ years (and in adults) with first relapse of ALL, with and without asparaginase hypersensitivity

3. OL, R, MC, active-controlled trial to evaluate $S$, PD equivalence/comparative efficacy of L-asparaginase encapsulated in erythrocytes in children from birth to $<18$ years with newly-diagnosed ALL

I. OL, single-dose, single-center, $\mathrm{R}$, crossover trial to assess the bioequivalence of oral mercaptopurine suspension to the tablet formulation in adults

I. R, parallel-group, blinded, single-center, multiple-dose trial to evaluate PK, PD,A, and S of recombinant L-asparaginase compared to native Escherichia coli asparaginase in children from I year to $<18$ years of age (and adults) with newly- diagnosed ALL

2. R, MC, double-blind trial to evaluate $S, P D$ equivalence, and $E$ of recombinant $L$-asparaginase compared to native $E$. coli asparaginase in children from I year to $<18$ years of age (and adults) with newly-diagnosed ALL

3. Noncontrolled, MC trial to evaluate PD,A, and S of recombinant L-asparaginase in children from birth to $<\mathrm{I}$ year of age with newlydiagnosed ALL

4. Three studies, listed separately under lymphoblastic lymphoma:"same as for condition treatment of acute lymphoblastic leukaemia"

I. OL R, controlled, parallel-group, MC trial to evaluate PK, PD, S, and E of rituximab add-on to standard CT in children 6 months to $<18$ years with advanced stage B-cell lymphoma (excluding primary mediastinal B-cell lymphoma), Burkitt and Burkitt-like lymphoma/leukemia

Abbreviations: ALL, acute lymphoblastic leukemia; PIP, pediatric investigation plan; OL, open-label; SA, single-arm; S, safety; F, feasibility; A, activity; CT, chemotherapy; SCT, stem cell transplantation; MC, multicenter; PK, pharmacokinetics; Ph+, Philadelphia chromosome-positive; CML, chronic myeloid leukemia; E, efficacy; R, randomized; Pop, population; PD, pharmacodynamics; CAR, chimeric antigen receptor; LL, lymphoblastic lymphoma. 


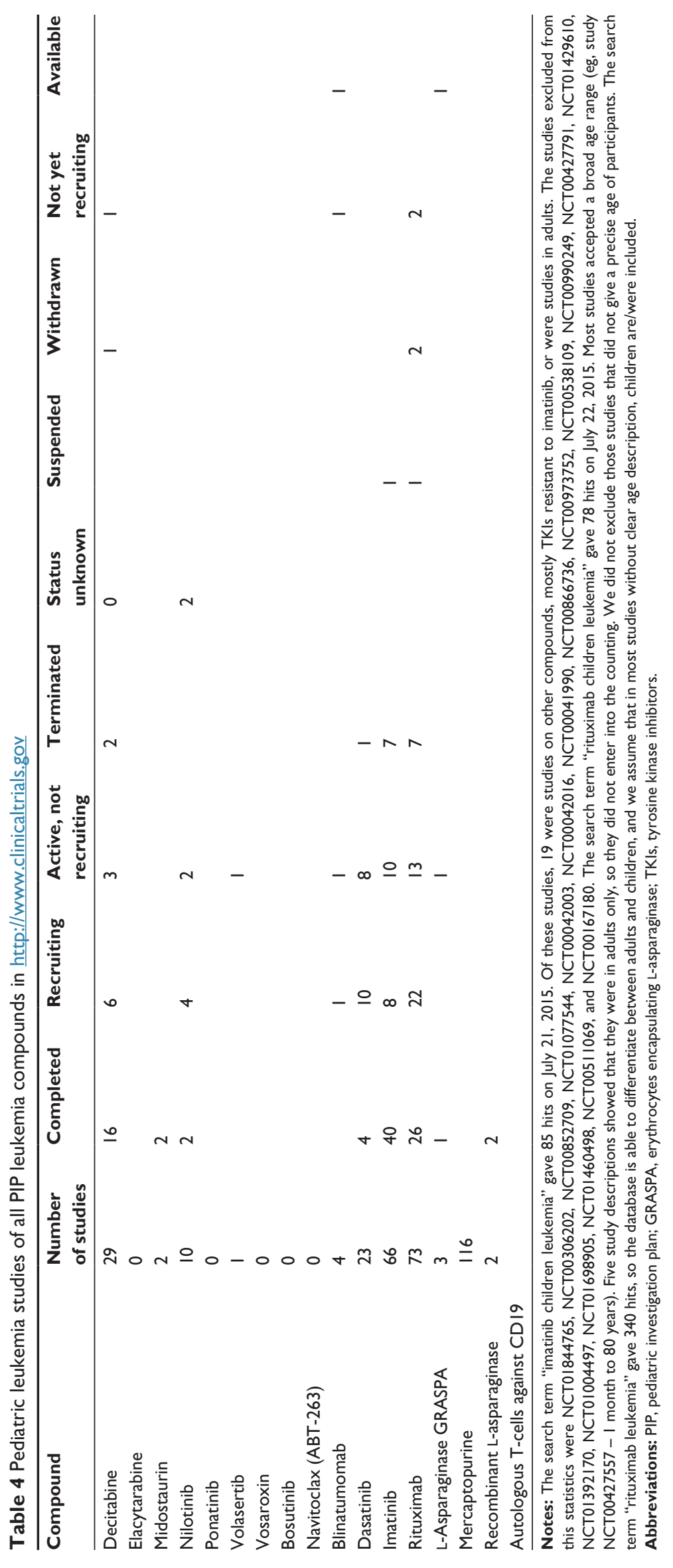


around the world as soon as the compound is available for any indication. The list of sponsors of these studies includes pharmaceutical companies, university hospitals, and cancer research centers in the US and worldwide (Table 4). The large number of ongoing and completed, non-EU decitabine studies raises questions about the relevance of the apparently redundant PIP studies (Table 5).

The first study in the decitabine PIP (EMEA-000555PIP01-09-M04, decision in 2013) corresponds to study number 1 in Table 5. The study is recruiting. Both clinical studies in this PIP should be completed by July 2021 (Table 2). Study number 1 is to be performed in R/R AML. Of the other decitabine studies, number 2 in Table 5, decitabine in children and young adults with R/R AML or ALL, was performed in
2002-2005 by the US National Cancer Institute. Furthermore, 27 other studies of decitabine in pediatric leukemia were started, 16 of which are already completed (Table 5). It is unlikely that the two PIP studies will add any relevant clinical data to that coming from the multiple clinical studies ongoing or already completed, but they kept/will keep the enrolled patients from participating in other studies with potentially more promising agents, some of which are discussed in the following paragraphs.

Cytarabine is part of the current standard induction CT for AML. Elacytarabine, an analog of cytarabine, was developed with the intent of overcoming resistance mechanisms. It is not yet clear if elacytarabine is an effective alternative to standard cytarabine in adult patients with acute leukemias,

Table 5 Decitabine clinical trials in leukemia children

\begin{tabular}{|c|c|c|c|c|}
\hline Number & Abbreviated title & NCT number & Age & Sponsor \\
\hline I & Decitabine + cytarabine in R/R AML & 01853228 & I month to 18 years & Jannsen Pharma \\
\hline 2 & Decitabine in $R / R$ AML or ALL & 00042796 & $\leq 21$ years & $\mathrm{NCl}$ \\
\hline 3 & Decitabine + genistein in ped $R / R$ malignancies & 02499861 & $2-21$ years & St Justine's Hospital \\
\hline 4 & Epigenetic reprogramming in relapsed $\mathrm{AML}$ & $024 \mid 2475$ & $\leq 25$ years & Medical College Wisconsin \\
\hline 5 & Decitabine + vorinostat $+C T$ in relapsed ALL & 1483690 & $I-2 \mid$ years & TACLC \\
\hline 6 & $A R-42$ + decitabine in AML & 01798901 & $\geq 3$ years & OSUCCC \\
\hline 7 & Decitabine + vorinostat $+C T$ in $R / R$ ALL or $L L$ & 00882206 & $2-60$ years & University of Minnesota \\
\hline 8 & Low-dose decitabine in R/R ALL & 00349596 & $?$ & MD Anderson Cancer Center \\
\hline 9 & Decitabine + GO in AML and HR MDS & 00882102 & $\geq 16$ years & MD Anderson Cancer Center \\
\hline 10 & Decitabine + valproic acid in R/R leukemia and MDS & 00075010 & $\geq 2$ years & MD Anderson Cancer Center \\
\hline II & Imatinib + decitabine in CML & 00054431 & $?$ & $\mathrm{NCl}$ \\
\hline \multirow[t]{2}{*}{12} & Decitabine for MDS and AML before allo-HSCT & 01806116 & $8-65$ years & Soochow Hospital, People's \\
\hline & & & & Republic of China \\
\hline 13 & Decitabine + PBSCT in relapsed leukemia, MDS, CML after BMT & 00002832 & $\leq 60$ years & MD Anderson Cancer Center \\
\hline 14 & Decitabine with induction $C T$ in $A M L$ & 01177540 & $\mathrm{I}-16$ years & Eisai Pharma \\
\hline 15 & Decitabine with or without valproic acid in MDS and AML & 00414310 & $?$ & MD Anderson Cancer Center \\
\hline 16 & Decitabine + GO in AML and HR MDS & $0096807 \mid$ & $\geq 16$ years & MD Anderson Cancer Center \\
\hline 17 & Decitabine in blast-phase CML relapsed to imatinib & 00042003 & $\geq 2$ years & Astex Pharma \\
\hline 18 & Decitabine in $C M L$ relapsed to imatinib & 00042016 & $\geq 2$ years & Astex Pharma \\
\hline 19 & Decitabine in $\mathrm{CML}$ relapsed to imatinib & 00041990 & $\geq 2$ years & Astex Pharma \\
\hline 20 & Decitabine for maintenance after first $C T$ for $A M L$ & 00416598 & $15-59$ years & $\mathrm{NCl}$ \\
\hline 21 & Decitabine in AML and MDS after allo-HSCT & 02264873 & $\mathrm{I}-30$ years & University of Florida \\
\hline 22 & Decitabine and two CT regimens in AML & 00943553 & $\mathrm{I}-16$ years & Eisai Pharma \\
\hline 23 & $\mathrm{CT}+\mathrm{PBSCT}$ in CML or acute leukemia & 00002831 & $15-55$ years & MD Anderson Cancer Center \\
\hline 24 & Phase I, dose-escalation study of decitabine & 00067808 & ? & MD Anderson Cancer Center \\
\hline 25 & Decitabine in MDS after azacytidine failure & 00113321 & I8-85 years & MD Anderson Cancer Center \\
\hline 26 & Decitabine in MDS & 00003361 & $\geq 15$ years & MSKCC \\
\hline \multirow[t]{2}{*}{27} & CHG vs decitabine in HR MDS & 01417767 & $16-80$ years & Shanghai Hospital, People's \\
\hline & & & & Republic of China \\
\hline 28 & Decitabine + cytarabine in MDS & 01674985 & $10-90$ years & CAMMS \\
\hline 29 & Decitabine in MDS & 02060409 & $17-90$ years & Samsung Medical Center \\
\hline
\end{tabular}

Notes: The search terms "decitabine leukemia children" gave 28 hits; two were in patients $\geq 60$ years and were removed (NCT02085408 and NCT0I04I703). Studies number 27-29 came up with the search terms "decitabine children", and as they aim at MDS and include also pediatric patients, they were added.

Abbreviations: NCT, National Clinical Trial; R/R, relapsed or refractory; AML, acute myeloid leukemia; ALL, acute lymphoblastic leukemia; NCl, National Cancer Institute; CT, chemotherapy; TACLC, Therapeutic Advances in Childhood Leukemia Consortium; OSUCCC, Ohio State University Comprehensive Cancer Center; LL, lymphoblastic lymphoma; GO, gemtuzumab ozogamicin; HR, high-risk; MDS, myelodysplastic syndrome; CML, chronic myeloid leukemia; HSCT, hematopoietic stem cell transplantation; PBSCT, peripheral blood stem cell transplantation; BMT, bone marrow transplantation; MSKCC, Memorial Sloan Kettering Cancer Center; CAMMS, Chinese Academy of Military Medical Sciences. 
especially when used in combination with additional agents such as anthracyclines. A Phase III clinical trial failed to show superiority of elacytarabine over the investigator's choice of therapy for R/R AML. ${ }^{28}$ The elacytarabine PIP decision dates from 2012, and the studies should be completed by 2019 (Table 2). The authors were unable to find a single pediatric clinical leukemia trial with this compound, and in view of the negative results mentioned by DiNardo et al, ${ }^{28}$ it appears questionable whether the two PIP studies make clinical or ethical sense.

Midostaurin is a first-generation FLT3 receptor TKI investigated for the treatment of AML and myelodysplastic syndrome. Early FLT3 inhibitors (including sunitinib, midostaurin, and lestaurtinib) demonstrated significant promise in preclinical models of FLT3-mutant AML. However, many of these compounds failed to achieve robust and sustained FLT3 inhibition in early clinical trials. Second-generation FLT3 inhibitors are now under development, ${ }^{29}$ and it is not known if they will fare better than the first-generation FLT3 TKIs. The search terms "midostaurin leukemia children" in http://www.clinicaltrials.gov identified two trials, both of which are completed (Table 6). There are 20 additional adult midostaurin studies in http://www.clinicaltrials.gov, including completed trials. The completed pediatric midostaurin trials correspond to the first two PIP studies listed in Table 2. The PIP was submitted in 2009 (the 09 in PIP number EMEA-000780-PIP01-09-M01 stands for 2009) and was modified once in 2014 (M01). The PIP studies should be completed by 2019 . The first study in Table 6 was performed in patients 3 months to $<18$ years in 2009-2014, and the second one in patients $\geq 14$ years in 2009-2012. Was this early exposure justified?

Nilotinib is a second-generation TKI approved for imatinib-resistant $\mathrm{Ph}+\mathrm{CML}$. The clinical trials in childhood leukemia are listed in Table 7. The first two trials in Table 7 correspond to studies 2 and 3 of those in the nilotinib PIP decision (Table 2). The first nilotinib PIP was submitted in 2008 and has so far been modified thrice (PIP number EMEA-000290-PIP01-08-M03). Modification number 3 was made in 2013. The first study in Table 7 is being performed in collaboration with the US National Cancer Institute (NCI). Both studies are still recruiting. The first study is planned to be concluded by 2020, the second by 2017, although the PIP decision asks for completion of all measures by September 2015. Table 7 also shows that nilotinib is presently being investigated in other, non-PIP-related clinical trials that include adolescents in Korea, India, the US, and Israel.

Ponatinib is a third-generation TKI for the treatment of CML and Ph+ ALL that was FDA-approved in 2014 for adults with $\mathrm{Ph}+$ leukemia resistant to other TKIs. ${ }^{2}$ The authors were unable to find any pediatric leukemia trials currently being performed with ponatinib. The PIP decision is from 2012, and the requested clinical trial should be finalized in 2020 (Table 2).

Volasertib is an inhibitor of polo-like kinase 1 that regulates numerous stages of mitosis and is overexpressed in many cancer types. Volasertib is presently in Phase III clinical trials in adult AML. So far, it is neither FDA- nor EMAapproved..$^{30}$ Volasertib was tested by the US-based Pediatric Preclinical Testing Program (PPTP), which concluded that volasertib showed potent in vitro activity against PPTP cell lines with no histotype selectivity and in vivo induced regressions in several xenograft models.

However, pharmacokinetic data suggest that mice tolerate higher systemic exposure to volasertib than humans, suggesting that the current results may over-estimate potential clinical efficacy against the childhood cancers studied. ${ }^{31}$

There is one volasertib pediatric leukemia clinical trial being performed (Table 8) which corresponds to the first PIP trial in Table 2. The trial is listed as "active, not recruiting". The trial with 40 pediatric patients is planned to be completed in 2016. The PIP was submitted in 2011. PIP number EMEA000674-PIP02-11 shows that this was the result of a second PIP negotiation round (PIP02), as opposed to all other PIPs documented in Table 1 that were agreed upon after the first round (PIP01). All volasertib PIP trials are expected to be finalized by 2023 (Table 2). There are numerous adult clinical trials listed in clinicaltrials.gov. The PPTP assessment of

Table 6 Midostaurin pediatric leukemia trials in http://www.clinicaltrials.gov

\begin{tabular}{|c|c|c|c|c|}
\hline Number & Abbreviated title & NCT number & Age & Sponsor \\
\hline I & $\begin{array}{l}\mathrm{OL}, \mathrm{DE}, \mathrm{S}, \mathrm{T} \text {, and } \mathrm{PK} \text { study of twice-daily oral } \\
\text { midostaurin and to evaluate preliminary clinical and } \mathrm{PD} \\
\text { response in pediatric patients with R/R leukemia }\end{array}$ & $0086628 I$ & 3 months to 17 years & Novartis \\
\hline 2 & $\begin{array}{l}\text { OL Phase I/II (Proof of Concept) Trial of midostaurin in } \\
\text { AML and HR MDS with either wild-type or mutated FLT3 }\end{array}$ & 00977782 & $\geq 14$ years & Novartis \\
\hline
\end{tabular}

Abbreviations: NCT, National Clinical Trial; OL, open-label; DE, dose-escalating; S, safety; T, tolerability; PK, pharmacokinetics; PD, pharmacodynamics; R/R, relapsed or refractory; AML, acute myeloid leukemia; HR, high-risk; MDS, myelodysplastic syndrome. 
Table 7 Nilotinib pediatric leukemia trials in http://www.clinicaltrials.gov

\begin{tabular}{|c|c|c|c|c|}
\hline Number & Abbreviated title & NCT number & Age & Sponsor \\
\hline $\mathrm{I}$ & Nilotinib in $\mathrm{Ph}+\mathrm{CML}$ children & 01844765 & $1-18$ years & Novartis \\
\hline 2 & $\mathrm{PK}$ of nilotinib in $\mathrm{Ph}+\mathrm{CML}$ or $\mathrm{ALL}$ children & 01077544 & $1-18$ years & Novartis \\
\hline 3 & Nilotinib and imatinib in ALL or CLL after donor SCT & 00702403 & ? & Fred Hutchinson CRC \\
\hline 4 & Nilotinib and combination CT in newly-diagnosed ALL & 00844298 & $\geq 15$ years & AMC, Korea \\
\hline 5 & $\mathrm{~h}$-Igf-I axis in CML children in remission & 01901666 & $?$ & PIMER, India \\
\hline 6 & Nilotinib vs imatinib in CML & 00760877 & $\geq 17$ years & Novartis \\
\hline 7 & $\mathrm{CT}+$ irradiation + PBSCT in AML or ALL respondent to a TKI & 00036738 & $\leq 70$ years & Fred Hutchinson CRC \\
\hline 8 & Nilotinib in CML Phase II study & 00129740 & $\geq 16$ years & MD Anderson Cancer Center \\
\hline 9 & Imatinib vs nilotinib in $\mathrm{CML}$ & 00802841 & $\geq 16$ years & Novartis \\
\hline 10 & Decision on imatinib vs other $\mathrm{TKI}$ in $\mathrm{CML}$ & 01762969 & $\geq 16$ years & Rabin Medical Center \\
\hline
\end{tabular}

Notes: One study (NCTO 32I70) tested pegylated interferon-alfa 2a in TKD-treated adolescents and adults; one study (NCT0I460498) investigated azacytidine in MRD CML treated with a TKI. The TKIs were not part of the experimental investigation. Study NCT01698905 included only adult patients. The three studies were not included in the table.

Abbreviations: NCT, National Clinical Trial; Ph+, Philadelphia chromosome-positive; CML, chronic myeloid leukemia; PK, pharmacokinetics; ALL, acute lymphoblastic leukemia; CLL, chronic lymphoblastic leukemia; SCT, stem cell transplantation; CRC, Cancer Research Center; CT, chemotherapy; AMC, Asian Medical Center; PIMER, Postgraduate Institute of Medical Education and Research; PBSCT, peripheral blood stem cell transplantation; AML, acute myeloid leukemia; TKI, tyrosine kinase inhibitor; MRD, minimal residual disease.

this compound raises ethical and scientific questions about whether children should be recruited into volasertib clinical trials before clinical efficacy in adults has been shown or instead into studies of agents with more promise in children are completed.

Vosaroxin is a quinolone derivative currently in clinical trials for $\mathrm{R} / \mathrm{R}$ AML and ovarian cancer. ${ }^{32}$ Vosaroxin failed to reach the primary endpoint in a study on R/R AML..$^{33}$ Nevertheless, the primary clinical investigator insisted that the combination of vosaroxin and cytarabine was better than placebo plus cytarabine. ${ }^{34}$ As of July 26, 2015, there were no trials found in clinicaltrials.gov using the search terms "vosaroxin children leukemia". The vosaroxin PIP trials should be finalized in July 2023. There are 13 adult trials in clinicaltrials.gov. The results reported by Levitan ${ }^{33}$ suggest that this is another example of a drug for which pediatric trials are scientifically and ethically questionable before better evidence of clinical efficacy in adults exists.

Chimeric antigen receptor-modified T-cells (CAR T-cells) with CD19 specificity are a novel promising therapy for B-cell malignancies. CAR T-cells are patient-derived T-cells, transduced to express a chimeric antigen receptor, which includes an anti-CD19 antibody fragment fused to a T-cell intracellular signaling domain. ${ }^{2}$ Studies identified in clinicaltrials.gov using the search terms "autologous T-cells CD19 children leukemia" are listed in Table 9. Sponsors include centers around the world: in the US, UK, and People's Republic of China. None of the studies in Table 9 are sponsored by the company that submitted the PIP shown in Table 2. Obviously, the CAR technology is already available to several clinical centers and collaborating universities. Should the sponsor get it approved as a drug, there will already be considerable pediatric experience, raising questions about what additional benefit the PIP studies will offer.

Navitoclax is an orally bioavailable inhibitor of the B-Cell Lymphoma 2 (BCL2) protein. BCL2 is often overexpressed in hematologic malignancies and prevents apoptosis of malignant cells. Targeting BCL2 is a novel approach for various hematologic malignancies. Navitoclax is currently being investigated in adults with B-cell lymphoproliferative disorders but is not approved anywhere. ${ }^{35}$ Clinicaltrials. gov lists no pediatric leukemia studies. The two PIP studies should be finalized in 2019. While promising, it is unclear whether or which children should be included in navitoclax clinical trials before clinical efficacy in adults has been shown.

Blinatumomab is a CD19/CD3-bispecific T-cell-engaging antibody that binds to CD3 T-cells and co-localizes them with

Table 8 Volasertib pediatric leukemia trials in http://www.clinicaltrials.gov

\begin{tabular}{llll}
\hline Number & Abbreviated title & NCT number & Age \\
\hline I & $\begin{array}{l}\text { Open-label dose-escalating trial to determine the } \\
\text { MTD-advanced cancers for whom no therapy is known }\end{array}$ & 0197I476 & Boehringer \\
& Ingelheim \\
\hline
\end{tabular}

Notes: The search terms "volasertib leukemia children" rendered two hits. However, study NCT0I721876 is in patients $\geq 65$ years only. This study was not included in this table.

Abbreviations: NCT, National Clinical Trial; MTD, maximum tolerated dose. 
Table 9 Pediatric leukemia trials with autologous T-cells against CD-19 in http://www.clinicaltrials.gov

\begin{tabular}{|c|c|c|c|c|}
\hline Number & Abbreviated title & NCT number & Age & Sponsor \\
\hline 1 & $\begin{array}{l}\text { A pediatric trial of genetically modified autologous } T \text {-cells } \\
\text { directed against } C D / 9 \text { for } R / C D I 9+A L L\end{array}$ & 01683279 & $1-26$ years & Seattle Children's Hospital \\
\hline 2 & $\begin{array}{l}\text { Redirected autologous T-cells engineered to contain } \\
\text { humanized anti-CDI9 in R/R CDI9+ leukemia and } \\
\text { lymphoma previously treated with cell therapy }\end{array}$ & 02374333 & $\mathrm{I}-24$ years & University of Pennsylvania \\
\hline 3 & $\begin{array}{l}\text { CARTI9 cells for patients with chemotherapy-resistant or } \\
\text { chemotherapy-refractory CDI9+ leukemia and lymphoma }\end{array}$ & 01626495 & $\mathrm{I}-24$ years & Children's Hospital of Philadelphia \\
\hline 4 & $\begin{array}{l}\text { Immunotherapy with CDI9 CAR T-cells for CDI9+ } \\
\text { hematological malignancies }\end{array}$ & 02443831 & $\leq 24$ years & University College London \\
\hline 5 & $\begin{array}{l}\text { Autologous T-lymphocytes genetically targeted to the } \\
\text { B-cell specific antigen CDI9 in pediatric and young adult } \\
\text { patients with relapsed B-cell ALL }\end{array}$ & 01860937 & $\leq 26$ years & $\begin{array}{l}\text { Memorial Sloan Kettering Cancer } \\
\text { Center }\end{array}$ \\
\hline 6 & $\begin{array}{l}\text { Anti-CD } 19 \text { CAR-transduced T-cell therapy for patients } \\
\text { with B-cell malignancies }\end{array}$ & 02456350 & $\mathrm{I}-85$ years & $\begin{array}{l}\text { Shenzhen Second People's Hospital, } \\
\text { People's Republic of China }\end{array}$ \\
\hline 7 & T-cells or EBV-specific CTLs, advanced B-cell NHL and CLL & 00709033 & $?$ & Baylor College of Medicine \\
\hline 8 & $\begin{array}{l}\text { Treatment of relapsed and/or chemotherapy-refractory } \\
\text { B-cell malignancy by CARTI } 9\end{array}$ & 01864889 & $5-90$ years & Chinese PLA General Hospital \\
\hline
\end{tabular}

Abbreviations: NCT, National Clinical Trial;ALL, acute lymphoblastic leukemia; CAR, chimeric antigen receptor; NHL, non-Hodgkin lymphoma; PLA, People's Liberation Army; $R / R$, relapsed or refractory; EBV, epstein barr virus; CTL, cytotoxic T-Lymphocyte; CLL, chronic lymphocytic leukemia.

CD19+ B-cells, activates the T-cells, and induces death of these B-cells. Blinatumomab was FDA-approved in December 2014 for Philadelphia chromosome-negative R/R B-cell precursor ALL in adults. ${ }^{36}$ Four ongoing pediatric leukemia trials were found in clinicaltrials.gov (Table 10). Only the first trial in Table 10 is listed as recruiting. It is run by the NCI which plans to recruit 598 patients $1-30$ years old by 2018 . Two out of the three other clinical trials in clinicaltrials.gov correspond to PIP studies. The NCI has prioritized, moved rapidly, and already opened this large study in children, adolescents, and young adults. All other studies on relapsed B-ALL will compete with this high-priority study for patients.

Dasatinib is a second-generation TKI that was FDAapproved in 2010 for newly-diagnosed adult $\mathrm{Ph}+\mathrm{CML}$ in the chronic phase. It is now also approved for $\mathrm{CML}$ and $\mathrm{Ph}+\mathrm{ALL}$ with resistance and intolerance to prior therapy, respectively. The studies listed in clinicaltrials.gov are shown in Table 11.
The three Bristol Meyer Squibb-sponsored studies on $\mathrm{R} / \mathrm{R}$ leukemia, pediatric CML, and Ph+ALL corresponding to the three PIP studies listed in Table 3 are to be finalized in 2018. There are 18 other studies ongoing in Korea, Japan, India, the US, and Israel that include children and adolescents.

Imatinib was the first TKI, now also used for multiple cancers, including $\mathrm{Ph}+\mathrm{CML}$, advanced gastrointestinal stroma tumor, $\mathrm{R} / \mathrm{R} \mathrm{Ph}+\mathrm{ALL}$, and several forms of myelodysplastic/myeloproliferative diseases. The FDA approved it in 2013 for children with Ph+ALL. There are 66 pediatric leukemia trials listed in clinicaltrials.gov, reflecting the high interest present in the oncology community (Table 4), of which 40 studies are already completed, eight still recruiting, 13 active but not recruiting, and seven terminated. This is another example of how many, non-PIP proposed but competing studies are done in children when a promising drug is identified.

Table 10 Blinatumomab pediatric leukemia trials in http://www.clinicaltrials.gov

\begin{tabular}{lllll}
\hline Number & Abbreviated title & NCT number & Age & Sponsor \\
\hline $\mathrm{I}$ & $\begin{array}{l}\text { Risk-stratified randomized trial of blinatumomab in first } \\
\text { relapse of childhood B-ALL }\end{array}$ & 02101853 & I-30 years \\
2 & $\begin{array}{l}\text { Single-arm MC trial preceded by dose evaluation to investigate } \\
\text { the E, S, and T of blinatumomab R/R B-precursor ALL }\end{array}$ & 01471782 & $\leq 17$ years & Amgen Pharma \\
& $\begin{array}{l}\text { Phase III trial to investigate the E, S, and T of blinatumomab as } \\
\text { consolidation therapy vs conventional consolidation CT HR } \\
\text { first relapse B-precursor ALL }\end{array}$ & 02393859 & $\leq 17$ years & Amgen Pharma \\
& OL MC expanded access protocol for R/R B-precursor ALL & 02187354 & $\leq 17$ years & Amgen Pharma
\end{tabular}

Notes: The search term "blinatumomab leukemia children" resulted in five hits. However, study NCT02003222 was in ALL patients of 30-70 years. This study was not entered into this table.

Abbreviations: NCT, National Clinical Trial; ALL, acute lymphoblastic leukemia; NCI, National Cancer Institute; MC, multicenter; E, efficacy; S, safety; T, tolerability; R/R, relapsed or refractory; CT, chemotherapy; HR, high-risk; OL, open-label. 
L-Asparaginase encapsulated in erythrocytes is a new galenic formulation of L-asparaginase, a wellestablished chemotherapeutic for adult and pediatric ALL ${ }^{37}$ Table 12 shows the three clinicaltrials.gov trials that correspond to the three PIP trials listed in Table 3. The third of these studies is already completed, the first is "active, not recruiting", and the second one is "available". There is no doubt about the efficacy of L-asparaginase, but the requirements to measure its immunogenicity, its "pharmacodynamic activity", and its "pharmacodynamic equivalence/comparative efficacy" in children are ethically questionable. Rare safety challenges are seldom detected in clinical trials, so a post-marketing safety observation study would appear to be more appropriate, since children enrolled in the PIP-proposed trials might not be available to enroll in other trials that offer greater chances of response or even cure.

Mercaptopurine is a well-known chemotherapeutic agent that is a standard part of many treatment schemes used in adult and pediatric leukemia. Clinicaltrials.gov lists 116 clinical trials in pediatric leukemia with mercaptopurine. A simple bioequivalence study for an oral suspension, compared to the tablet, performed in adults, makes sense.

Recombinant L-asparaginase is another L-asparaginase preparation. Table 13 shows that clinicaltrials.gov lists two trials, both of which are completed. Investigation of efficacy in two separate trials in children is ethically questionable, since the efficacy of L-asparaginase is well known. A safety assessment as part of a post-marketing observation would seem to be more appropriate.

\section{Discussion}

An evaluation of the PIP decisions suggests that not all PDCO-mandated trials are practical to perform and some do not make sense scientifically or raise ethical concerns about possible exploitation of patients.

There are now several new TKIs. The high number of adult patients with $\mathrm{Ph}+$ leukemias is obviously an incentive to develop further TKIs. But childhood leukemias are rare. Only $3 \%-4 \%$ of childhood ALL is $\mathrm{Ph}+$, while in adults, it is $25 \% .{ }^{38} \mathrm{CML}$ exists in children, but it accounts for only $2 \%-3 \%$ of children with leukemia. ${ }^{39}$ The subfraction of $\mathrm{Ph}+$

Table I I Dasatinib pediatric leukemia trials in http://www.clinicaltrials.gov

\begin{tabular}{|c|c|c|c|c|}
\hline Number & Abbreviated title & NCT number & Age & Sponsor \\
\hline I & Dasatinib in R/R leukemia & 00306202 & 12 months to 20 years & BMS \\
\hline 2 & Dasatinib in CML & 00777036 & $\leq 18$ years & BMS \\
\hline 3 & Dasatinib and CCT in ALL & 00720109 & $2-30$ years & $\mathrm{NCl}$ \\
\hline 4 & Dasatinib in malignancy not responding to imatinib & 00316953 & $|-2|$ years & $\mathrm{NCl}$ \\
\hline 5 & Newly-diagnosed ALL & 00549848 & $\leq 18$ years & St Jude $\mathrm{CRH}$ \\
\hline 6 & $\mathrm{Ph}+\mathrm{ALL}$ & 01460160 & $1-17$ years & BMS \\
\hline 7 & Nilotinib in $\mathrm{Ph}+\mathrm{CML}$ & 01844765 & $1-18$ years & Novartis \\
\hline 8 & $\mathrm{PK}$ nilotinib in $\mathrm{Ph}+\mathrm{CML}$ or $\mathrm{ALL}$ & 01077544 & $1-18$ years & Novartis \\
\hline 9 & Dasatinib in imatinib-resistant or intolerant CML & 00866736 & $\geq 15$ years & Kanto CML Study Group \\
\hline 10 & Ruxolitinib or dasatinib with CT in Ph-like ALL & 02420717 & $\geq 10$ years & MD Anderson Cancer Center \\
\hline II & Dasatinib in CML in Japan & $014644 \mid I$ & $\geq 20$ months & Kanto CML Study Group \\
\hline 12 & Dasatinib in CML & 00254423 & $\geq 16$ years & MD Anderson Cancer Center \\
\hline 13 & Assessment of Gh-lgf-I axis in CML in remission & 01901666 & $?$ & PIMER, India \\
\hline 14 & $\begin{array}{l}\mathrm{CT}+\text { irradiation + PBSCT in ALL or CML } \\
\text { responding to } \mathrm{TKI}\end{array}$ & 00036738 & $\leq 70$ years & Hutchinson CRC \\
\hline 15 & Dasatinib stop trial in CML & 01627132 & $\geq 15$ years & Shimousa HSG \\
\hline 16 & Dasatinib $+\mathrm{CT}$ in adults with $\mathrm{Ph}+\mathrm{ALL}$ & 01004497 & $15-65$ years & Catholic University of Korea \\
\hline 17 & Dasatinib in CML or ALL & 00103701 & $\geq 14$ years & BMS \\
\hline 18 & Dasatinib in CML & $0|88756|$ & $\geq 15$ years & Kanto CML Study Group \\
\hline 19 & Korean post-marketing surveillance of dasatinib & 01464047 & $?$ & BMS \\
\hline 20 & IL-II and dasatinib in CML & 00493 I8I & $?$ & MD Anderson Cancer Center \\
\hline 21 & Pegasys in CML & 01392170 & $\geq 16$ years & MD Anderson Cancer Center \\
\hline 22 & Azacytidine in MRD CML & 01460498 & $\geq 16$ years & MD Anderson Cancer Center \\
\hline 23 & Treatment modification in CML & 01762969 & $\geq 16$ years & Rabin Medical Center \\
\hline
\end{tabular}

Notes: The listed studies were the result of the search terms "dasatinib children leukemia", which resulted in 26 hits. Study NCT00364286 had only recruited adults; studies NCT00563290 and NCT00070499 recruited only patients $\geq 18$ years old. These studies were not included in the table.

Abbreviations: NCT, National Clinical Trial; R/R, relapsed or refractory; BMS, Bristol Meyer Squibb; CML, chronic myeloid leukemia; CCT, combination chemotherapy; ALL, acute lymphoblastic leukemia; NCl, National Cancer Institute; CRH, Children Research Hospital; Ph+, Philadelphia chromosome-positive; PK, pharmacokinetics; CT, chemotherapy; PIMER, Postgraduate Institute of Medical Education and Research; PBSCT, peripheral blood stem cell transplantation; TKI, tyrosine kinase inhibitor; CRC, Cancer Research Center; HSG, Hematology Study Group; IL-I I, interleukin I I; MRD, minimal residual disease. 
Table I 2 Erythrocytes encapsulating L-asparaginase children leukemia

\begin{tabular}{|c|c|c|c|c|}
\hline Number & Abbreviated title & NCT number & Age & Sponsor \\
\hline I & GRASPA in relapsed ALL & 01518517 & $\mathrm{I}-55$ years & ERYtech Pharma \\
\hline 2 & $\begin{array}{l}\text { EAP: safety of GRASPA }{ }^{\circledR} \text { with PCT in ALL patients }<55 \text { years } \\
\text { at risk to receive other formulation of asparaginase }\end{array}$ & 02197650 & $\mathrm{I}-55$ years & ERYtech Pharma \\
\hline 3 & GRASPA in relapsed ALL & 00723346 & $\mathrm{I}-55$ years & ERYtech Pharma \\
\hline
\end{tabular}

Notes: The search term "erythrocytes L-asparaginase children leukemia" gave eight hits on July 2I, 2015. Four of these studies used ordinary L-asparaginase (NCT00022737, NCT00070 174, NCT00550992, NCT00458848) and were not included in the table. Furthermore, study NCT01910428 was in adults only and was also not included in this table. Abbreviations: NCT, National Clinical Trial; GRASPA, erythrocytes encapsulating L-asparaginase; ALL, acute lymphoblastic leukemia; EAP, Expanded Access Program; PCT, polychemotherapy.

pediatric leukemia patients that are $\mathrm{R} / \mathrm{R}$ to a first TKI is very small. Pediatric investigation of the second TKI was already initiated by the NCI but will take many years to recruit sufficient patients. Beginning simultaneous comparable trials for the next TKIs becomes questionable. Concerns about the one-size-fits-all logic of the AML standard PIP were confirmed by a review of the PIP decisions for bosutinib and ponatinib. For bosutinib, the PIP asks for a study on $\mathrm{R} / \mathrm{R}$ CML resistant to prior TKI therapy, while for ponatinib, a study is requested in children with malignant diseases for which no effective treatment is known. If they are started at all, these PIP studies compete for recruitment with other, more reasonable studies.

There are several new formulations of chemotherapeutic agents, for example, L-asparaginase. There is in-depth research on how to better adapt treatment with L-asparaginase to the individual child's genetic predisposition..$^{40}$ We doubt that studies that investigate safety and "pharmacodynamic activity" of L-asparaginase in first relapsed ALL or comparison of the efficacy of two formulations of L-asparaginase (Table 3) are the best treatment options for these patients.

For several compounds, the PIP was negotiated early, and the studies were started years before proof of efficacy or safety in adults, or before studies that compared their efficacy with other new drugs were available, for example, midostaurin and volasertib.

Will it be ethical to initiate the navitoclax PIP studies?

Children with R/R ALL leukemia are fighting for their lives, and many of them will die. Compounds with the greatest chances of improving survival should be studied first. This requires prioritization of drugs, studies, and of potential subjects. This cannot be done with a "standard PIP" approach. Forcing companies to "propose" studies that recruit these children into PDCO-dictated trials without such prioritization is a waste of industrial, regulatory, academic, and patient/parent resources and is not in the best interest of these children.

As the clinicaltrials.gov data shows, whenever a potential therapeutic benefit of a new compound is expected, clinical studies are opened worldwide in both adults and children. When additional PDCO-mandated trials are initiated (eg, R/R ALL), they compete for recruitment.

Once an innovative adult compound is approved anywhere and thus available, leukemia trials start in adults and children. There are 40 pediatric leukemia studies with imatinib completed, ten active but not recruiting, eight recruiting, and seven already terminated (Table 4). What relevance can the two additional imatinib PIP trials have? Other examples include dasatinib, nilotinib, and rituximab, where the PIP studies will consume resources and patients but are unlikely to have any significant impact.

The pediatric oncology community initially supported both US and EU pediatric legislation. They were frustrated to see that industry developed powerful new drugs against adult cancer, and felt themselves and their patients neglected.

The role of the EMA oncology PIP decisions is now increasingly discussed by academic pediatric oncologists. Adamson, for example, considers that for childhood cancer

Table I 3 Recombinant L-asparaginase children leukemia

\begin{tabular}{lllll}
\hline Number & Abbreviated title & NCT number & Age & Sponsor \\
\hline $\mathrm{I}$ & $\begin{array}{l}\text { Comparative E and S of two asparaginase preparations } \\
\text { in children with previously untreated ALL }\end{array}$ & 00784017 & I-18 years & Medac Pharma \\
2 & $\begin{array}{l}\text { E and S of recombinant asparaginase in infants with } \\
\text { previously untreated ALL }\end{array}$ & 00983138 & $<$ year & Medac Pharma \\
\hline
\end{tabular}

Notes: The search terms "recombinant L-asparaginase children leukemia" on July 2I, 2015 gave six hits. However, four of these studies (NCT00720I09, NCT02I0I853, NCT02003222, NCT02003222) did not use recombinant asparaginase.

Abbreviations: NCT, National Clinical Trial; E, efficacy; S, safety; ALL, acute lymphoblastic leukemia. 
drug development, the most notable impact of the US and EU legislative initiatives has been the increasing engagement of the biopharmaceutical industry with investigators from academia in planning for pediatric drug development. He also describes how the PIP discussions at an early stage of development are, especially for Phase III trial plans, quite speculative. He identifies as the underlying cause that the discussion with the regulatory authorities is drug-centric and not disease-centric. ${ }^{41,42}$ Both Adamson and Vassal have expressed the wish that less waivers should be issued by the regulatory authorities. ${ }^{1,5,43}$ Vassal also observes that regulatory changes in the US and Europe have changed the environment for pediatric drug development, and addresses several unintended consequences, including the fact that legislation only causes adult cancer drugs to be studied in children, and that industry does not pursue first-in-children indications. He describes the futility of complex Phase III discussions at too early a point in development, that each drug is assessed independently, that too many PIPs are approved for the same indication, and that the feasibility of simultaneous drug trials in these rare-disease populations is disregarded. $\mathrm{He}$ proposes a modification of the PIP process specifically for anticancer drugs. ${ }^{2}$ Vassal et al explicitly called for oncology class waivers to be revoked. ${ }^{43}$

A new EMA class waiver decision was published in July 2015. The class waivers for a number of adult cancers, for example, liver and intra-hepatic bile duct carcinoma, were revoked. Furthermore, waivers for drug classes that target a number of cancers, including breast carcinoma and prostate carcinoma, have been revised. ${ }^{44,45}$ Obviously, EMA/PDCO want to expand the PIP system. The press release on this decision has the headline "Stimulating the development of medicines for children". ${ }^{46}$ This is misleading. The EU pediatric regulation is not designed to develop drugs for children; it also makes drug development for adults more cumbersome. The review of the data outlined above suggests that a flawed approach could be expanded rather than improved.

The challenge of improving the treatment of children with leukemia appears at first glance to be a challenge of science. Science is a part of the challenge, but the challenge is more complex. The challenge is how to use the potential power of innovation to improve the treatment of childhood leukemia.

All players in drug development have their own conflicts of interests. Pediatric oncology institutions want bigger budgets and more publications, as well as access to potentially useful new treatments. Regulatory authorities want to justify their role as well as an expanded role in directing pharmaceutical drug development in public debate and opinion. Pharmaceutical companies are market-driven with clear business aims that involve return on investment.

Most specialists agree that steps toward the solution to these challenges (there are many types and subtypes of childhood leukemia) should come from biomedical research, but it is unclear whether or how this will come about. Perhaps, it will be possible to graft a CAR from a childhood leukemia patient onto a T-cell. Perhaps, computer programs will one day predict the direction(s) of mutations and preprogram the fitting of CARs. However, the authors disagree with Adamson and Vassal about the value of merely increasing engagement of biopharmaceutical industry in discussing childhood diseases, certainly not by the current EMA PIP process. The evidence presented suggests that the EMA's leukemia decisions are not in the best interest of children. They impede rather than advance pediatric oncology research, could decrease public trust into pediatric clinical trials, and potentially, if not actually, cause harm to children. Forcing the pharmaceutical industry to enroll children into questionable studies prevents their recruitment into more useful studies. Increasing attention to pediatric oncology by expanding rather than improving the flawed PIP is not the same as finding better therapies.

The US approach offers a possible alternative. For example, blinatumomab was approved in the US at the end of 2014, while it is not yet licensed in the EU as of early August 2015. Once a compound like this is approved, it can be used in children off-label. And in fact, the US NCI has started a large blinatumomab clinical trial in first relapsed ALL. There is no counterpart to the US NCI in the EU. The Innovative Therapies for Children with $\mathrm{Cancer}^{47}$ is an academic consortium. We would argue that one key element to help both adults and children with cancer is faster approval of effective drugs in adults and a prioritized, less globally redundant approach to pediatric studies that acknowledge the very limited number of available patients.

EMA/PDCO's insistence on studies in ultrarare conditions has been discussed in other publications that focus on PDCO decisions related to metastasized melanoma. The frequency of pediatric patients with metastasized melanoma that need systemic treatment is $\sim 10 \%$ of what EMA/PDCO claims. There are now two international multicenter clinical trials recruiting adolescents with metastasized melanoma, and a warning has been published to ethics committees/institutional review boards worldwide to screen PDCO-triggered trials to prevent the abuse of children in unethical "ghost studies". ${ }^{48-50}$ 
The term "therapeutic hostages" has been proposed to characterize this abuse, alluding to the term "therapeutic orphans" coined by Shirkey in 1963. ${ }^{48,51}$ The data presented here suggest similar concerns could be raised for children with $\mathrm{R} / \mathrm{R}$ leukemia.

The questionable childhood leukemia PIP trials mentioned above have several potential adverse consequences. Recruitment into questionable studies prevents patients from enrolling in more meaningful studies, can create false hope in patients and parents, has the potential to destroy public confidence in pediatric clinical trials, and can cause companies that try to perform these studies to perform them in the developing world, as most US and (hopefully) also most EU centers will not participate.

Pediatric legislation is modifying the relationship between the major players in medicine and research. For many years, very few in clinical academia were involved with regulatory authorities or their decisions. This needs to change. Academic pediatric oncologists need to become more involved in analyzing regulatory decisions that affect their patients. PIP decisions and all trials listed in clinicaltrials. gov will have to be analyzed as will publications resulting from PIP-triggered trials to see if the concerns explained in this paper are confirmed. If so, it may be necessary for the cooperative groups involved in pediatric leukemia and oncology to take steps to try to improve or replace the current PIP system. Other stakeholders including industry, trade associations, parents, and support groups should also become more involved in assessing the impact of the PIP system on children with leukemia.

At present, there is insufficient incentive to develop truly new drugs targeted against childhood leukemia. A reward system is needed that appeals to a combination of several factors: science, skills in drug development from laboratory to the bedside, academic competition, financial greed, clinical empathy, personal or family concern, and a strong vision. For developing new treatments in childhood leukemia and other cancers, new thinking is needed. One possible model is the US Creating Hope Act that reward the first three companies that find a cure against a rare disease with a transferable voucher for priority review. The first such voucher was sold for $\sim \$$ US 68 Mio. ${ }^{1}$

Children cannot vote, so they are inadequately considered by legislators who approve biomedical research funding. Children with cancer are rare and therefore provide little promise of profits for the market-driven biopharmaceutical industry. Yet, the Food and Drug Administration Modernization Act approach to provide financial incentives (in the form of prolonged market exclusivity) to study adult drugs in children was very effective. Clearly, financial incentives work in a market-driven system. Why not then create an incentive by offering reward for companies, institutions, or even individuals that reach drug development milestones for one of the many subgroups of childhood leukemia? Instead of creating a bureaucracy that chokes drug developers and potentially exploits or harms children, perhaps, the discussion should shift toward looking at ways to create mechanisms to reward market-driven pediatric oncology research.

\section{Conclusion}

The EMA/PDCO PIP process is not effectively helping children with leukemia and is not in their best interest. It should be redesigned to more closely match the FDA approach.

Drugs being developed for conditions that occur only in children should not involve the PDCO.

Drugs being developed for childhood leukemia (and other conditions both potentially lethal and extremely rare in children) should be prioritized so that the most promising drugs are studied first and only after sufficient evidence of efficacy and safety in adults.

Academic pediatric oncologists should take a more active role in reviewing and commenting on regulatory processes and decisions that affect their patients.

Incentives need to be developed that reward novel new approaches to drug development for pediatric leukemia and are consistent with the market forces that currently drive the biopharmaceutical industry.

\section{Acknowledgment}

We thank Professor Thomas Kuehne, University Children's Hospital, Basel, Switzerland, for initial high-level feedback on the concept of this paper.

\section{Disclosure}

Klaus Rose has worked for more than 20 years in pharmaceutical industry and is now an independent consultant in pediatric drug development. Philip D Walson has been a clinician and academic researcher throughout his professional life. Potential conflicts include his private consulting company (Walson Consulting, LLC) that has provided fee for service consultation to the pharmaceutical industry and contract research organizations as well as to US and EU not-for-profit governmental funded research organizations (eg, NICHD, FP7 health projects and the Innovative Medicines Initiative) and paid participation in numerous conferences devoted to pediatric clinical trials and drug development. No grants or 
funds have been involved in the authorship of this paper. The authors declare no other conflicts of interest in this work.

\section{References}

1. Adamson PC. Improving the outcome for children with cancer: development of targeted new agents. CA Cancer J Clin. 2015;65: 212-220

2. Annesley CE, Brown P. Novel agents for the treatment of childhood acute leukemia. Ther Adv Hematol. 2015;6(2):61-79.

3. Snyder KM, Donoghue M, Helms WS, Reaman G. Chapter 35: development of drugs for pediatric cancers. In: Mulberg AE, Murphy D, Dunne J, Mathis L, editors. Pediatric Drug Development - Concepts and Applications. 2nd ed. Chichester, UK: Wiley Blackwell; 2013: 438-452.

4. Mussai FJ, Yap C, Mitchell C, Kearns P. Challenges of clinical trial design for targeted agents against pediatric leukemias. Front Oncol. 2015;4:374.

5. Vassal G, Zwaan CM, Ashley D, et al. New drugs for children and adolescents with cancer: the need for novel development pathways (Improving cancer care for children and young people 3). Lancet Oncol. 2013;14:e117-e124.

6. Creutzig U, van den Heuvel-Eibrink MM, Gibson B, et al; AML Committee of the International BFM Study Group. Diagnosis and management of acute myeloid leukemia in children and adolescents: recommendations from an international expert panel. Blood. 2012;120(16):3187-3205.

7. Cooper SL, Brown PAB. Treatment of pediatric acute lymphoblastic leukemia. Pediatr Clin North Am. 2015;62(1):61-73.

8. Pritchard-Jones K, Pieters R, Reaman GH, et al. Sustaining innovation and improvement in the treatment of childhood cancer: lessons from high-income countries. Lancet Oncol. 2013;14(3):e95-e103.

9. Boklan J. Little patients, losing patience: pediatric cancer drug development. Mol Cancer Ther. 2006;5(8):1905-1908.

10. Wax PM. Elixirs, diluents, and the passage of the 1938 federal food, drug and cosmetic act. Ann Intern Med. 1995;122:456-461.

11. Taussig HB. A study of the German outbreak of phocomelia. JAMA. 1962;180:1106-1114

12. Hilts PJ. Protecting America's Health: The FDA, Business, and One Hundred Years of Regulation. New York, USA: Alfred A Knopf; 2003.

13. European Medicines Agency (EMA): Available from: http://www ema.europa.eu/ema/index.jsp?curl=pages/about_us/general/general_ content_000235.jsp. No date.

14. Regulation (EC) No 1901/2006 Of The European Parliament And Of The Council of 12 December 2006 on medicinal products for paediatric use and amending Regulation (EEC) No 1768/92, Directive 2001/20/EC, Directive 2001/83/EC and Regulation (EC) No 726/2004 2006. Available from: http://ec.europa.eu/health/files/eudralex/vol-1/ reg_2006_1901/reg_2006_1901_en.pdf.

15. Rose K. Chapter 28: pediatric pharmaceutical legislation in the USA and EU and their impact on adult and pediatric drug development. In: Bar-Shalom D, Rose K, editors. Pediatric Formulations - A Roadmap. AAPS and Springer; 2014:405-420.

16. Rose K. Chapter 25: clinical testing in children. In: Bar-Shalom D, Rose K, editors. Pediatric Formulations - A Roadmap. AAPS and Springer; 2014:365-376.

17. Mulberg AE, Silber SA, van den Anker JN. Pediatric Drug Development - Concepts and Applications. New Jersey, USA: Wiley \& Son; 2009.

18. Mulberg AE, Murphy D, Dunne J, Mathis L. Pediatric Drug Development - Concepts and Applications. 2nd ed. New Jersey, USA: Wiley \& Son; 2013.

19. Farber S, Diamond LK, Mercer RD, et al. Temporary remissions in acute leukemia in children produced by folic acid and antagonist, 4-aminopteroyl-glutamic acid (aminopterin). N Engl J Med. 1948;238: $787-793$
20. Frei E, Freireich EJ, Gehan E, et al. Studies of sequential and combination antimetabolite therapy in acute leukemia: 6-mercaptopurine and methotrexate. Blood. 1961;18(4):431-454.

21. Pinkel D. Five-year follow-up of "total therapy" of child- hood lymphocytic leukemia. JAMA. 1971;216:648-652.

22. Pui C-H, Evans WE. A 50-year journey to cure childhood acute lymphoblastic leukemia. Semin Hematol. 2013;50(3):185-196.

23. Tommasi P. Writing applications for paediatric investigation plans and waivers. Med Writing. 2012;21(2):1-4.

24. Rose K. A paediatric investigation plan case study. Pharm Med. 2012;26(5):287-295.

25. European Medicines Agency (EMA). Standard Acute Myeloid Leukaemia Paediatric Investigation Plan. 2013. Available from: http:// www.ema.europa.eu/docs/en_GB/document_library/Regulatory_and_ procedural_guideline/2013/02/WC500139182.pdf.

26. European Medicines Agency (EMA). Opinons and Decisions on Pediatric Investigation Plans. Available from: http://www.ema. europa.eu/ema/index.jsp?curl=pages/medicines/landing/pip_search. jsp\&mid=WC0b01ac058001d129. No date.

27. Malik P, Cashen AF. Decitabine in the treatment of acute myeloid leukemia in elderly patients. Cancer Manag Res. 2014;6:53-61.

28. DiNardo CC, O’Brien S, Ghandi VV, Ravandi F. Elacytarabine (CP-4055) in the treatment of acute myeloid leukemia. Future Oncol. 2013;9(8):1073-1082.

29. Wander SA, Levis MJ, Fathi AT. The evolving role of FLT3 inhibitors in acute myeloid leukemia: quizartinib and beyond. Ther Adv Hematol. 2014;5(3):65-77.

30. Liu X. Targeting polo-like kinases: a promising therapeutic approach for cancer treatment. Transl Oncol. 2015;8(3):185-195.

31. Gorlick R, Kolb EA, Keir ST, et al. Initial testing (stage 1) of the polo-like kinase inhibitor volasertib (BI 6727), by the Pediatric Preclinical Testing Program. Pediatr Blood Cancer. 2014;61(1): 158-164.

32. Abbas JA, Stuart RK. Vosaroxin: a novel antineoplastic quinolone. Expert Opin Investig Drugs. 2012;21(8):1223-1233.

33. Levitan D. Vosaroxin Fails to Improve Overall Survival in AML, But Certain Subgroups Benefit. Cancer Network; 2014. Available from: http://www.cancernetwork.com/leukemia-lymphoma/vosaroxin-failsimprove-overall-survival-aml-certain-subgroups-benefit.

34. Ravandi F, Ritchie E, Sayar H, et al. LBA-6 Improved Survival in Patients with First Relapsed or Refractory Acute Myeloid Leukemia (AML) with Vosaroxin Plus Cytarabine Versus Placbo Plus Cytarabine: Results of a Phase 3 Double-Blind Randomized Controlled Multinational Study (VALOR). In: Abstract, American Society of Hematology (ASH) Conference, 2014. Available from: https://ash.confex.com/ash/2014/ webprogram/Paper77078.html.

35. Anderson MA, Huang D, Roberts A. Targeting BCL2 for the treatment of lymphoid malignancies. Semin Hematol. 2014;51: 219-227.

36. Hoffman L, Gore L. Blinatumomab, a bi-specific anti-CD19/CD3 $\mathrm{BiTE}^{\circledR}$ antibody for the treatment of acute lymphoblastic leukemia: perspectives and current pediatric applications. Front Oncol. 2014;4:63.

37. Salzer WL, Asselin BL, Plourde PV, Corn T, Hunger SP. Development of asparaginase Erwinia chrysanthemi for the treatment of acute lymphoblastic leukemia. Ann NY Acad Sci. 2014;1329:81-92.

38. Kolb A, Pan Q, Ladanyi M, Steinherz PG. Imatinib mesylate in Philadelphia chromosome- positive leukemia of childhood. Cancer. 2003;98(12):2643-2650.

39. Bernt KM, Hunger SP. Current concepts in pediatric Philadelphia chromosome-positive acute lymphoblastic leukemia. Front Oncol. 2014;4:54

40. Ben Tanfous M, Sharif-Askari B, Ceppi F, et al. Polymorphisms of asparaginase pathway and asparaginase-related complications in children with acute lymphoblastic leukemia. Clin Cancer Res. 2015; 21(2):329-334.

41. Adamson PC, Houghton PJ, Perilongo G, Pritchard-Jones K. Drug discovery in paediatric oncology: roadblocks to progress. Nat Rev Clin Oncol. 2014;11:732-739. 
42. Adamson PC. Unintended consequences of regulatory initiatives in childhood cancer drug development. JAMA Pediatr. 2013;167(10): 886-887.

43. Vassal G, Geoerger B, Morland B. Is the European pediatric medicine regulation working for children and adolescents with cancer? Clin Cancer Res. 2013;19(6):1315-1325.

44. EMA Decision. CW/0001/2015 of 23 July 2015 on Class Waivers, in Accordance with Regulation (EC) No 1901/2006 of the European Parliament and of the Council. 2015. Available from: http://www. ema.europa.eu/docs/en_GB/document_library/Other/2015/07/ WC500190385.pdf.

45. EMA. EMA/PDCO Summary Report on the Review of the List of Granted Class Waivers. 2015. Available from: http://www.ema.europa.eu/docs/ en_GB/document_library/Other/2015/07/WC500190384.pdf.

46. EMA Press Release. Stimulating the Development of Medicines for Children. 2015. Available from: http://www.ema.europa.eu/docs/ en_GB/document_library/Press_release/2015/07/WC500190382.pdf.
47. Innovative Therapies for Children with Cancer (ITCC). Available from: http://www.itcc-consortium.org. No date.

48. Rose K. European union pediatric legislation jeopardizes worldwide, timely future advances in the care of children with cancer. Clin Ther. 2014;36(2):163-177.

49. Rose K, Senn S. Drug development: EU paediatric legislation, the European Medicines Agency and its Paediatric Committee - adolescents' melanoma as a paradigm. Pharm Stat. 2014;13(4):211-213.

50. Rose K, Kummer H. A New Ethical Challenge for Institutional Review Boards (IRBs)/Ethics Committees (ECs) in the assessment of pediatric clinical trials. Children. 2015;2:198-210.

51. Shirkey H. Therapeutic orphans. J Pediatr. 1968;72(1):119-120. 


\section{Supplementary materials}

Table SI EMA/PDCO PIP decisions oncology

\begin{tabular}{|c|c|c|c|c|c|}
\hline Substance & Indication & PIP number & $\begin{array}{l}\text { Decision } \\
\text { year }\end{array}$ & Until & Classification \\
\hline Aut T-Cells ag CDI9 & CT-resistant CDI9+ leukemia or lymphoma & EMEA-00I654-PIPOI-I4 & 2015 & DEC 2021 & Leukemia \\
\hline TH-302 & Ewing and soft tissue sarcoma & EMEA-00 I 483-PIPOI-I3 & 2015 & DEC 2026 & Solid tumor \\
\hline MK-8669,/AP23573 & Solid malignant tumors & EMEA-000458-PIP0I-08 & 2010 & JUN 2019 & Solid tumor \\
\hline HSV-TK gene & Operable supratentorial HGG & EMEA-000 I40-PIPOI-07 & 2008 & $4 y$ after ini & Solid tumor \\
\hline MAB (MPDL3280A) & PD-LI pos malignant neoplasms & EMEA-00I638-PIPOI-I4 & 2015 & JUN 2015 & Solid tumor \\
\hline MAB (MK-3475) & Melanoma or PD-LI+ tumor/lymphoma & EMEA-00 I 474-PIPOI-I3 & 2014 & OCT 2023 & Solid tumor \\
\hline Aprepitant & Nausea and vomiting in chemo/after OP & EMEA-000I44-PIP0I-07-M05 & 2014 & OCT 2014 & Adjuvant to $\mathrm{CT} / \mathrm{SCT}$ \\
\hline Navitoclax (ABT & ALL, NHL & EMEA-000478-PIPOI-08-M0I & 2011 & DEC 2019 & Leukemia \\
\hline Bevacizumab & HGG & EMEA-000056-PIP03-I0-M02 & 2014 & SEP 2016 & Solid tumor \\
\hline Bevacizumab & RMS and non-RMS soft tissue sarcoma & EMEA-000056-PIP0I-07-M02 & 2014 & SEP 2016 & Solid tumor \\
\hline Blinatumomab & ALL & EMEA-000574-PIP02-12 & 2014 & JUL 2023 & Leukemia \\
\hline Bosutinib & CML & EMEA-000727-PIP0I-09 & 2010 & DEC 2016 & Leukemia \\
\hline Brentuximab & Anaplastic LCL and $\mathrm{HL}$ & EMEA-000980-PIPOI-I0-M02 & 2014 & DEC 2018 & Lymphoma \\
\hline Cabozantinib & Solid tumors w/MET, VEGFR, and/or RET PA & EMEA-00II43-PIPOI-II & 2012 & DEC 2016 & Solid tumor \\
\hline Casopitant & $\mathrm{CT}$ related and post OP nausea and vomiting & EMEA-000I54-PIPOI-07 & 2009 & MAY 2013 & Adjuvant to $\mathrm{CT} / \mathrm{SCT}$ \\
\hline Cediranib maleate & HGG & EMEA-000477-PIP0I-08 & 2010 & DEC 2015 & Solid tumor \\
\hline MAB (NSC764038) & Neuroblastoma & EMEA-00I285-PIPOI-I2-M0I & 2013 & JAN 2014 & Solid tumor \\
\hline MAB (APN3II) & Neuroblastoma & EMEA-00।3|4-PIPOI-I2 & 2014 & DEC 2016 & Solid tumor \\
\hline Cilengitide & HGG & EMEA-000550-PIP02-I0-M0I & 2013 & NOV 2018 & Solid tumor \\
\hline Cobimetinib & $\begin{array}{l}\text { Malignancies w/Ras, Raf or MEK pathway } \\
\text { activation }\end{array}$ & EMEA-00 I425-PIPOI-I3-M0I & 2014 & JUN 2026 & Solid tumor \\
\hline Cyclophosphamide & Malignant diseases & EMEA-000530-PIP02-II & 2012 & MAR 2015 & Malignant diseases \\
\hline Dabrafenib & $\begin{array}{l}\text { BRAF V600-mutant melanomas and solid } \\
\text { tumors }\end{array}$ & EMEA-00 I I47-PIPOI-I I0M02 & 2014 & JUL 2019 & Solid tumor \\
\hline Dasatinib & $\begin{array}{l}\mathrm{Ph}+(\mathrm{BCR}-\mathrm{ABL} \text { translocation }) \text {-positive } \\
\mathrm{ALL} \text { and } \mathrm{AML}\end{array}$ & EMEA-000567-PIPOI-09-M04 & 2013 & JUN 2018 & Leukemia \\
\hline Decitabine & AML & EMEA-000555-PIPOI-09-M04 & 2013 & JUL 202I & Leukemia \\
\hline Denosumab & $\begin{array}{l}\text { Giant cell tumor of bone and more, } \\
\text { see below }\end{array}$ & EMEA-000I45-PIP0I-07-M07 & 2015 & NOV 2017 & Solid tumor \\
\hline Dextran & $\begin{array}{l}\text { Visualization of lymphatic drainage of solid } \\
\text { malignant tumors for diagnostic purposes }\end{array}$ & EMEA-00I255-PIPOI-II & 2012 & OCT 2015 & Diagnostic \\
\hline Docetaxel & Nasopharyngeal carcinoma & EMEA-000029-PIPOI-07 & 2008 & SEP 2009 & Solid tumor \\
\hline Elacytarabine & AML & EMEA-00II2I-PIPOI-I0 & 2012 & SEP 2019 & Leukemia \\
\hline Eltrombopag & $\begin{array}{l}\text { TP due to treated M/L leukemia or solid } \\
\text { tumors }\end{array}$ & EMEA-000I70-PIP02-I0-M02 & 2015 & DEC 2019 & Adjuvant to $\mathrm{CT} / \mathrm{SCT}$ \\
\hline Enzastaurin & High-risk B-cell NHL & EMEA-001033-PIP02-II & 2013 & JUN 2022 & Lymphoma \\
\hline Eribulin & RMS and non-RMS soft tissue sarcoma & EMEA-00I26I-PIPOI-II-MOI & 2015 & NOV 2029 & Solid tumor \\
\hline Febuxostat & Hyperuricemia tumor lysis syndrome & EMEA-00I4I7-PIPOI-I2 & 2014 & DEC 2017 & Adjuvant to $\mathrm{CT} / \mathrm{SCT}$ \\
\hline Fosaprepitant & $\begin{array}{l}\text { Nausea and vomiting in chemotherapy in } R \\
\text { after FLT }\end{array}$ & EMEA-000406-PIP0I-08-M04 & 2014 & OCT 2014 & Adjuvant to $\mathrm{CT} / \mathrm{SCT}$ \\
\hline Glucarpidase & Methotrexate toxicity & EMEA-00I39I-PIPOI-I2 & 2013 & JUN 2012 & Adjuvant to $\mathrm{CT} / \mathrm{SCT}$ \\
\hline HSV TK & Adjunctive treatment in $\mathrm{HCT}$ & EMEA-00I370-PIP02-I3 & 2014 & DEC 2022 & Adjuvant to $\mathrm{CT} / \mathrm{SCT}$ \\
\hline Idelalisib & Lymphomas & EMEA-00I350-PIP02-I3-M0I & 2014 & JUL 202I & Lymphoma \\
\hline Imatinib mesilate & $\begin{array}{l}\mathrm{Ph}+(\mathrm{BCR}-\mathrm{ABL} \text { translocation)-positive } \\
\mathrm{ALL} \text { et al }\end{array}$ & EMEA-000463-PIPOI-08-M03 & 2012 & JUN 20II & Leukemia \\
\hline Ipilimumab & $\begin{array}{l}\text { Malignomas except melanoma, NS, H\&L } \\
\text { tissue }\end{array}$ & EMEA-000 I I7-PIPOI-07-M07 & 2015 & JUN 2018 & Solid tumor \\
\hline Ipilimumab & Melanoma & EMEA-000 I I 7-PIP02-I0-M03 & 2014 & JUN 2018 & Solid tumor \\
\hline L-AGN in erys & ALL & EMEA-00034I-PIP02-09-M0I & 2014 & DEC 2020 & Leukemia \\
\hline Lenvatinib & $\begin{array}{l}\text { Follicular or papillary thyroid cancer; } \\
\text { osteosarcoma }\end{array}$ & EMEA-00 I I I9-PIP02-I2-M02 & 2014 & DEC 2022 & Solid tumor \\
\hline Mercaptopurine & ALL & EMEA-000350-PIP0I-08 & 2009 & DEC 2009 & Leukemia \\
\hline Midostaurin & $\begin{array}{l}\text { AML, malignant mastocytosis, mast cell } \\
\text { leukemia }\end{array}$ & EMEA-000780-PIP0I-09-M0I & 2014 & DEC 2019 & Leukemia \\
\hline
\end{tabular}


Table SI (Continued)

\begin{tabular}{|c|c|c|c|c|c|}
\hline Substance & Indication & PIP number & $\begin{array}{l}\text { Decision } \\
\text { year }\end{array}$ & Until & Classification \\
\hline ABT-869 & $\begin{array}{l}\text { Solid malignant tumors (refractory to } \\
\text { standard therapy) }\end{array}$ & EMEA-000389-PIPOI-08-M0I & 2011 & JUN 2017 & Solid tumor \\
\hline Nilotinib & Gastrointestinal stromal tumor, CML & EMEA-000290-PIPO I-08-M03 & 2013 & SEP 2015 & Leukemia \\
\hline Nivolumab & $\begin{array}{l}\text { Malignomas except NS, haematopoiet and } \\
\text { lymphoid tissue }\end{array}$ & EMEA-00I407-PIPOI-I2 & 2014 & AUG 2024 & Solid tumor \\
\hline Obinutuzumab & ALL, mature B-cell lymphoma & EMEA-00I 207-PIPOI-II & 2013 & JUN 2024 & Lymphoma \\
\hline Ombrabulin & RMS and non-RMS soft tissue sarcoma & EMEA-000800-PIP0I-09-M0I & 2011 & DEC 2018 & Solid tumor \\
\hline Paclitaxel & $\begin{array}{l}\text { Solid malignomas, CT-naïve metastasized } \\
\text { melanoma }\end{array}$ & EMEA-00I308-PIPOI-I 2 & 2013 & DEC 2022 & Solid tumor \\
\hline Pazopanib & RMS, non-RMS, soft tissue S, EwingS & EMEA-00060 I-PIPOI-09-M02 & 2014 & SEP 202I & Solid tumor \\
\hline Pixantrone & NHL & EMEA-0007I 3-PIP02-I0-M03 & 2015 & NOV 2023 & Lymphoma \\
\hline Plerixafor & Myelosuppression caused by chemotherapy & EMEA-000 I 74-PIPO I-07-M03 & 2013 & JUN 2017 & Adjuvant to CT/SCT \\
\hline XM22 & Chemotherapy-induced febrile neutropenia & EMEA-00I0I9-PIPOI-I0-M02 & 2014 & APR 2018 & Adjuvant to CT/SCT \\
\hline Ponatinib & $\begin{array}{l}\text { CML resistant or intolerant to prior TKI } \\
\text { therapy }\end{array}$ & EMEA-00I I86-PIPOI-II & 2012 & DEC 2020 & Leukemia \\
\hline Pralatrexate & NHL, HL, T-cell lymphoma & EMEA-0006I9-PIP02-10 & 2010 & MAR 202I & Lymphoma \\
\hline RO5 185426 & BRAF V600 + unresectable melanoma & EMEA-000978-PIPOI-I0 & 2011 & MAR 2017 & Solid tumor \\
\hline CSF/fusion protein & $\begin{array}{l}\text { Prevention of chemotherapy-induced } \\
\text { neutropenia }\end{array}$ & EMEA-00I042-PIP02-II & 2011 & DEC 2014 & Adjuvant to $\mathrm{CT} / \mathrm{SCT}$ \\
\hline MAB (RO4858696) & Ewing sarcoma & EMEA-00028I-PIP0I-08-M02 & 2009 & DEC 2016 & Solid tumor \\
\hline Recombinant L-AGN & ALL and lymphoblastic lymphoma & EMEA-0000 I 3-PIPO I-07-M03 & 2013 & NOV 2012 & Leukemia \\
\hline Regorafenib & Solid malignant tumor(s) & EMEA-00I I 78-PIPOI-II-M0I & 2014 & DEC 2020 & Solid tumor \\
\hline Rituximab & $\begin{array}{l}\text { Autoimmune arthritis, diffuse } \\
\text { large B-cell } L\end{array}$ & EMEA-000308-PIPOI-08-M02 & 2012 & JUN 2019 & Leukemia \\
\hline Sonidegib & Medulloblastoma & EMEA-000880-PIP02-I I-M02 & 2013 & DEC 2024 & Solid tumor \\
\hline Sunitinib & Gastrointestinal stromal tumor & EMEA-000342-PIPO I-08-M04 & 2015 & JUN 2014 & Solid tumor \\
\hline Talimogene & Solid malignant non-CNS tumors & EMEA-00I25 I-PIPOI-I I & 2013 & DEC 2024 & Solid tumor \\
\hline Tivantinib & Hepatoblastoma & EMEA-00I 284-PIPOI-12 & 2012 & Refused W & Solid tumor \\
\hline Trametinib & Melanoma & EMEA-00 I I77-PIPOI-II-M0I & 2014 & OCT 2019 & Solid tumor \\
\hline Treosulfan & Preparation of AHSCT & EMEA-000883-PIPO I-I0-M02 & 2014 & DEC 2016 & Adjuvant to CT/SCT \\
\hline Vandetanib & Medullary thyroid carcinoma & EMEA-000052-PIP0I-07-M03 & 2013 & OCT 20II & Solid tumor \\
\hline Veliparib & HGG & EMEA-000499-PIP02-I0 & 2011 & DEC 2020 & Solid tumor \\
\hline Volasertib & AML & EMEA-000674-PIP02-II & 2013 & DEC 2023 & Leukemia \\
\hline Vosaroxin & AML & EMEA-00I450-PIPOI-I3 & 2014 & JUL 2023 & Leukemia \\
\hline
\end{tabular}

Notes: Denosumab indications: I) Bone loss associated with sex hormone ablative therapy; 2) Prevention of skeletal related events in patients with bone metastases; 3) Treatment of chronic idiopathic arthritis (including rheumatoid arthritis, psoriatic arthritis, ankylosing spondylitis, and juvenile idiopathic arthritis); and 4) Treatment of giant cell tumor of bone.

Abbreviations: L-AGN, L-Asparaginase; CT, chemotherapy; HGG, high grade glioma; LCL, large cell lymphoma; HL, Hodgkin lymphoma; NHL, Non-Hodgkin lymphoma; ALL, acute lymphoblastic leukemia; AML, acute myelogenous leukemia; PA, pathway activation; Ph+, Philadelphia chromosome-positive; AHSCT, allogeneic hematopoietic stem cell transplant; TKI, tyrosine kinase inhibitor; TP, thrombocytopenia; R, remission; FLT, front line therapy; HCT, hematopoietic cell transplantation; H\&L, hematopoietic and lymphoid tissue; S, sarcoma; L, lymphoma; CDI9+, CDI9 positive; PIP, pediatric investigation plan; JAN, January; MAR, March; APR, April; Jun, June; JUL, July, SEP, September; OCT, October; NOV, November; DEC, December; $4 y$ after ini, 4 years after initiation; Refused W, refused waiver; MAB, monoclonal antibody; w/, with.

Table S2 PIP decisions wrongly listed under 'oncology' by EMA (5 decisions)

\begin{tabular}{llll}
\hline Compound & Indication & PIP number & Until \\
\hline Alemtuzumab & MS & EMEA-00I072-PIPOI-I0 & SEP20I8 \\
MAB (LY2I27399) & MS and chronic autoimmune arthritis & EMEA-000802-PIP0I-09 & DEC2023 \\
Darbepoetin alfa & Symptomatic anemia associated with chronic renal failure (CRF) & EMEA-000329-PIP02-09-M03 & DEC20I6 \\
Briakinumab & Psoriasis vulgaris & EMEA-000552-PIP0I-09-M0I & NOV20I6 \\
Rituximab & Granulomatosis w. polyangiitis (Wegener's), microscopic polyangiitis & EMEA-000308-PIP02-II & MAY20I6 \\
\hline
\end{tabular}

Abbreviations: MS, multiple sclerosis; PIP, pediatric investigation plan; SEP, September; NOV, November; DEC, December; MAB, monoclonal antibody; EMA, European Medicines Agency. 
Table S3 PIP decisions removed from analysis as listed in duplication (3 decisions)

\begin{tabular}{llll}
\hline Pazopanib & RMS, non-RMS STS, Ewing sarcoma & EMEA-00060I-PIP0I-09-M02 & SEP202I \\
Recomb L-AGN & ALL and lymphoblastic lymphoma & EMEA-0000I3-PIP0I-07-M03 & NOV20I2 \\
CSF/fusion protein & Prevention of CT induced neutropenia & EMEA-00I042-PIP0I-10 & Refused W \\
\hline
\end{tabular}

Abbreviations: STS, soft tissue sarcoma; Recomb L-AGN, recombinant L-Asparaginase; CSF, colony-stimulating factor; CT, chemotherapy; ALL, acute lymphoblastic leukemia; PIP, pediatric investigation plan; NOV, November; DEC, December; RMS, rhabdomyosarkoma; Refused W, refused waiver.

Table S4 PIP decision listed as PIP modification; text of decision shows it is now a waiver

\begin{tabular}{llll}
\hline Compound & Indication & PIP number & $\begin{array}{l}\text { Decision } \\
\text { year }\end{array}$ \\
\hline MAGE-A3 & Melanoma & EMEA-00I099-PIP02-II-M0I & 2014 \\
\hline
\end{tabular}

Abbreviation: PIP, pediatric investigation plan.

\section{Publish your work in this journal}

Risk Management and Healthcare Policy is an international, peerreviewed, open access journal focusing on all aspects of public health, policy, and preventative measures to promote good health and improve morbidity and mortality in the population. The journal welcomes submitted papers covering original research, basic science, clinical \& epidemio- logical studies, reviews and evaluations, guidelines, expert opinion and commentary, case reports and extended reports. The manuscript management system is completely online and includes a very quick and fair peerreview system, which is all easy to use. Visit http://www.dovepress.com/ testimonials.php to read real quotes from published authors.

\footnotetext{
Submit your manuscript here: http://www.dovepress.com/risk-management-and-healthcare-policy-journal
} 